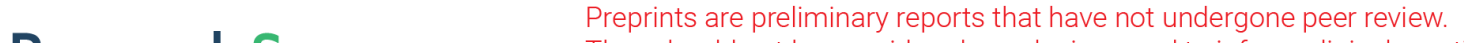 They should not be considered conclusive, used to inform clinical practice, or referenced by the media as validated information. \\ The characteristics of weather-related wind load parameters and wind power quality over the Dabanchen strong gale area
}

\section{Yu Xin ( $\sim$ learnerxy@163.com )}

Institute of Desert Meteorology, China Meteorology Administration, Urumqi https://orcid.org/00000002-8546-0545

\section{Zonhui Liu}

Institute of Desert Meteorology, China Meteorology Administration, Urumqi

\section{Qing He}

Institute of Desert Meteorology, China Meteorology Administration, Urumqi

\section{Research Article}

Keywords: Dabanchen Canyon, inland strong gale area, weather-related wind load parameter characteristics, structural turbulence, complex mountainous terrain

Posted Date: December 13th, 2021

DOI: https://doi.org/10.21203/rs.3.rs-1161718/v1

License: (a) This work is licensed under a Creative Commons Attribution 4.0 International License. Read Full License 


\title{
The characteristics of weather-related wind load parameters and wind power quality over the Dabanchen strong gale area
}

\author{
Yu XIN ${ }^{1}$, Zonhui LIU ${ }^{1}$, Qing HE $^{1}$ \\ 1 Institute of Desert Meteorology, China Meteorology Administration, Urumqi, Urumqi 830002
}

\begin{abstract}
Analysis of data from cup and ultrasonic anemometers on a $100 \mathrm{~m}$-tall wind mast in the Dabanchen Canyon reveals that the turbulence intensities, gust factors, and peak factors measured by cup anemometers tend to be severely undervalued compared to longitudinal values from an ultrasonic anemometer, and onsite three-dimensional measurement data are preferred for weather-related wind load calculation. This difference is related to the rotating responses of cup anemometers during wind speed acceleration or deceleration and the higher vertical fluctuation speeds driven by dynamic interactions with the sloped canyon terrain. The higher lateral turbulence is key consideration for determining wind turbine classes in Danbanchen strong wind area. The longitudinal gust and peak factors under wind speeds exceeding $25.0 \mathrm{~m} \mathrm{~s}^{-1}$ are comparable with those of typhoon-prone open, flat regions. The chances of high turbulence and unstable stratification convective processes are very high; thus, wind power collection efficiencies are not high. Except the longitudinal turbulence integral scale, China's windresistance codes are not applicable due to occasional undesirable strong gales with extraordinary turbulence structures. The measured vertical power spectral density of fluctuating wind in the high-frequency domain cannot reflect the rapidly adapting features of the vast terrain under strong gales.
\end{abstract}

Keywords: Dabanchen Canyon, inland strong gale area, weather-related wind load parameter characteristics, structural turbulence, complex mountainous terrain

\section{Introduction}

The Dabanchen Canyon is in an air flow channel with a width of approximately 15 to $30 \mathrm{~km}$ and a length of approximately $80 \mathrm{~km}$, connecting two basins in northern and southern Xinjiang. The average altitude of the mountains on both sides exceeds $2000 \mathrm{~m}$, with a maximum altitude of over 3,500 m (Xin et al., 2015(a); Xin et al.,2015(b); Su and Xin et al., 2021; Li et al.,2012). Within the canyon, two lakes - Chaiwuopu Lake and Salt Lake - cover approximately $28 \mathrm{~km}^{2}$ and $35 \mathrm{~km}^{2}$, respectively, and are accompanied by desert grasslands, meadow grasslands, shrubs and semishrub deserts, sand, and Gobi (Fig 1). The average slope angles at the bottom of the

\footnotetext{
${ }^{1}$ Funding: This work was supported by the National Nature Science Foundation of China through the key project: The Research of Earth-atmosphere Exchange Process and Atmospheric Boundary Layer Structure in case of Undulating Terrain over Taklamakan Desert (41830968) and the Basic Scientific Operational Research funding of the National Commonweal Research Institute for the project: Several Technical Studies Oriented the Near-surface Boundary Layer Prediction Improvement Over Wind Farms(IDM2021007).

Corresponding author address: Xin Yu, Institute of Desert Meteorology, Urumqi, China Meteorological Administration, Jianguo Road 327, Tianshan District, Urumqi, China, 830002. Email: xinyu@idm.cn or learnerxy@163.com
} 
canyon vary from 1.5 to 2.0 degrees, with individual slopes up to 4.2 degrees (Xin et al., 2015(a); Xin et al.,2015(b)). Influenced by the funnel effect, northwest and southeast gales prevail year-round. Downward momentum propagating along the steep terrain of the canyon due to western cold-front synoptics or upward airflow along the steep terrain behind South Xinjiang High-pressure systems can produce higher vertical velocities, with wind attack angles greater than $\pm 3^{\circ}$ (Su and Xin et al., 2021). China's "Wind-resistant Design Specification for Highway Bridges (JTG/T 3360-01-2018, 2018)" (abbreviated JTG/T 3360-01) regards the canyon as one of the most hazardous regions (R1) because the basic wind speed at $10 \mathrm{~m}$ height measured by the local meteorological station during the 10-year return period was $33.9 \mathrm{~m} \mathrm{~s}^{-1}$. Based on the correlations of simultaneous observation data from the 31003 meteorological wind mast (Xin et al., 2015(a); Xin et al.,2015(b)), which was installed in the canyon by the Fourth National Wind Energy Resources Detail Investigation and Assessment in China, and the nearby Dabanchen Meteorological Station number 51473, including the homogenized climatic annual maximum wind speed and annual mean wind speed during the period of 1991-2010 (Chen H W, 2010), the deduced design baseline wind speed (corrected by the standard air density) during a 50-year return period was $38.2 \mathrm{~m} \mathrm{~s}^{-1}$, with a yearly mean wind speed at $70 \mathrm{~m}$ height of approximately 10.6, as stipulated by China's "Specification for data inspection and correction of wind power plant meteorological observation (GB/T 37523-2019, 2019)" (abbreviated GB/T 37523).
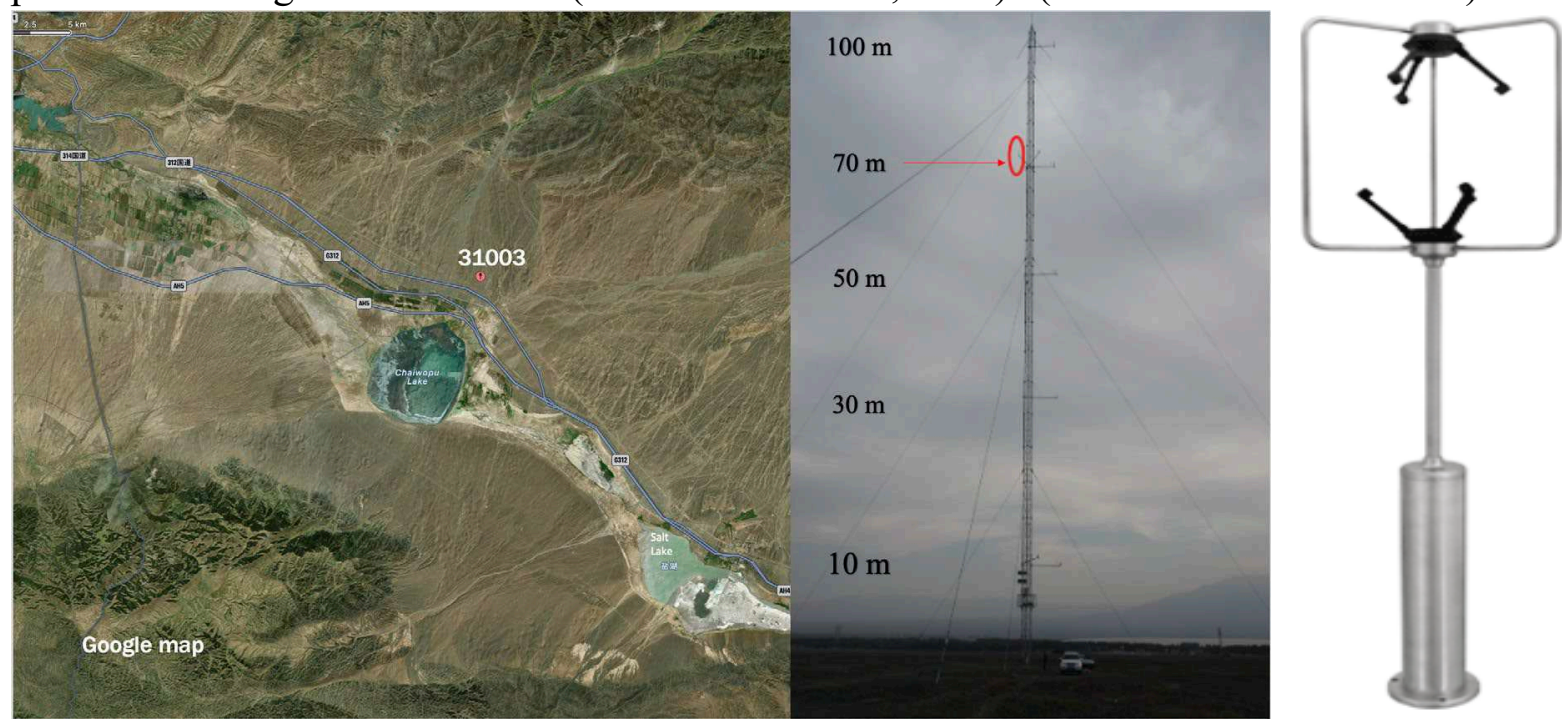

Fig. 1 Surroundings of the 31003 wind-measurement anemometer mast and its ultrasonic anemometer installed at $70 \mathrm{~m}$ height in the Dabanchen Canyon

The abovementioned wind characteristics expose a twofold complexity in this region. High winds potentially lead to a cost challenge between wind turbine fatigue loading design and higher-efficiency wind turbine collection as well as the damage resistance of wind-turbine blades under extremely strong gales. At the wind-measurement site of the 31003 meteorological wind mast (Fig 1), according to the determination of wind turbine classes in IEC-61400-3-1 (2019), class I indicated by the yearly average wind speed $\left(10.6 \mathrm{~m} \mathrm{~s}^{-1}\right)$ at $70 \mathrm{~m}$ height does not correspond to class II indicated by the basic wind speed $\left(38.2 \mathrm{~m} \mathrm{~s}^{-1}\right)$ during a 50 -year return period, regardless of the turbulence effect. Apparently, ignoring turbulence easily causes uncertainty in determining wind turbine design and has an impact on wind energy resource assessment and wind power forecasting. Another pressing issue is that the applicabilities of 
designed turbulence intensity (abbreviated TI; the turbulence intensity derived from cup anemometer data analysis is abbreviated $I$ in this work) profiles at an effective height of $\mathrm{z}$ (abbreviated $I_{z}$ ) for structural wind loading engineering based on China's "Load Code for the Design of Building Structures (GB50009-2012, 2012)" (abbreviated GB50009) are still uncertain, and this includes gust factor (abbreviated GF) models (specified $\beta_{z g}$ ), even though they have been obtained in previous works. For example, the derived wind shear exponent $(\alpha)$ below $100 \mathrm{~m}$ at the 31003 mast ( $\alpha=0.11$ ) (Xin, et al., 2015(a)) is comparable with the nominal $\alpha$ value corresponding to Exposure Category A (nominal $\alpha=0.12$ ) following the principles of JTG/T 3360-01(2018) or GB50009(2012), and the derived surface roughness length $\left(z_{0}\right.$, $\left.z_{0}=0.02 \mathrm{~m}\right)(\mathrm{Xin}$, et al. $2015(\mathrm{~b}))$ is comparable with the nominal $z_{0}$ value corresponding to Exposure Category A $\left(0.01<\right.$ nominal $\left.z_{0}<0.05\right)$. However, the derived TI at $10 \mathrm{~m}$ height $\left(I_{10}\right.$, $I_{10}=0.18$ ) at the 31003 mast (Xin, et al., 2015(a)) is obviously greater than the nominal $I_{10}$ value under the condition of Exposure Category B (nominal $I_{10}=0.14$ ). From this viewpoint, a conservative designed TI or GF value at effective height $\mathrm{z}$ arises naturally from the empirical formulas $I_{z}=I_{10}(z / 10)^{-\alpha}$ and $\beta_{z g}=1+2 g I_{10}(z / 10)^{-\alpha}$ stipulated by GB50009(2012) due to the inappropriately employed smaller nominal $I_{10}$ compared to the $I_{10}$ derived onsite. Upon further analyzing the $\alpha, z_{0}$, and $I_{10}$ values of two other masts from previous calculations (Xin, et al., 2015(a); Xin, et al. 2015(b)), the same issues occur. A similar issue occurs in JTG/T 336001(2018), where the longitudinal TI (abbreviated $I_{u}$; the longitudinal turbulence intensity derived from ultrasonic anemometer data analysis is abbreviated $I_{u}$ in this work.) profiles at effective height $\mathrm{z}$ are characterized by $I_{z, u}=\ln \left(z_{0} / z\right)$ and nominal $z_{0}$ values are taken from the 4 exposure category descriptions.

However, due to airflow extrusion or friction caused by heterogeneous topography and surface vegetation under terrain canalization, the average wind speed and TI profiles do not vary with altitude (Xin, et al., 2015(a)), as GB-50009(2012) and JTG/T 3360-01(2018) stipulate. Therefore, the extent of turbulence seems to be an inherent property of $\alpha$ or $z_{0}$, and the designed TI profiles $\left(I_{z}\right)$ appear to be modified by the terrain $\alpha$ or $z_{0}$, although the $\alpha$ and $z_{0}$ values are not essential factors in producing turbulence, which can also be related to atmospheric stability, such as nonstationary wind (i.e., squall lines or downbursts). The theorical foundations of both codes including numerical simulation experiments for wind turbine fatigue load calculation ( $\mathrm{He}$ et al., 2020; Liu et al.,2020; Ren et al.,2018), which are based on stationary winds for relatively open flat areas and on wind tunnel tests, are not directly applied for large, complex mountainous terrain frequently accompanied by unstable stratification synoptics. It is very difficult for these methods to accurately reflect rapid and high-amplitude nonstationary wind evolution processes due to either ignoring the large-scale synoptic background or restrictions imposed by wind tunnel sizes and configurations. Furthermore, the turbulence calculation accuracy is restricted by the wind tunnel size. Thus, the collection of necessary onsite observational data should be prioritized (An et al.,2019; Kozmar et al., 2021). However, to our knowledge, little research on weatherrelated wind loading parameters under strong unstable convective regimes has been performed.

In addition to the above issue that the terrain $\alpha$ or $z_{0}$ is not sufficient for TI calculation, it is worth noting that in fatigue load calculations for small or large wind turbines based on measured wind data, most meteorological engineers have regarded $I$ as $I_{u}$ and fit the normal turbulence model (NTM) described in IEC 61400-3-1 (2019), probably due to the high cost of deploying 3component observational instruments. We are currently uncertain whether these previous results 
are applicable in the Dabanchen Canyon. In fact, the IEC 61400-3-1(2019) standard not only attaches importance to building a $I_{u}$ reference NTM but also considers the influence of the lateral and vertical TI (the lateral and vertical turbulence intensity derived from ultrasonic anemometer data analysis are abbreviated $I_{v}$ and $I_{w}$, respectively, in this work) on $I_{v}$ and $I_{w}$ reference NTM with $I_{v}=0.7 I_{u}$ and $I_{w}=0.50 I_{u}$, referencing Burton's proposal (2001), in which $I_{v}=0.8 I_{u}$ and $I_{w}=0.50 I_{u}$. From this viewpoint, IEC 61400-3-1(2019) emphasizes the impact of lateral wind to a greater extent than Burton's proposal. In wind turbine fatigue loading calculation, IEC 61400-301(2019) also considers the turbulence structure of a site, i.e., the ratios of the three turbulence components, to estimate the site complexity and correct the reference NTM by accounting for the distortion of the turbulent flow. When only cup anemometer instruments are used, IEC 61400-3-1(2019) also recommends the use of empirical constants to revise the reference NTM with respect to terrain complexity. Therefore, it is necessary to determine whether the correction of the NTM based on terrain complexity can compensate for the associated impacts on sites located in large canyons, such as that examined in this work.

Meanwhile, with the widespread installation of $110 \mathrm{kV}-750 \mathrm{kV}$ overhead transmission lines and towers across the mountain valley due to increasing power requirements, many wind deflection flashover or transmission line damage accidents related to airflow and simultaneous structure vibrations have often occurred due to strong winds (the average wind speed at a height of $10 \mathrm{~m}$ is greater than $10.8 \mathrm{~m} \mathrm{~s}^{-1}$, corresponding to a Beaufort number greater than 6), and individual towers, which are even designed according to relevant standards or codes (Davenport, 1961; Davenport and Sparling, 1992; GB50545, 2010), have occasionally collapsed under nonstationary winds (i.e., downbursts, squall lines, and thunderstorms). Consequently, the dynamic behavior of high-voltage overhead transmission caused by wind-induced vibration and its effect on transmission towers has been an important issue for engineers and researchers in the electric power industry (An et al., 2019; He et al., 2020; Zhou et al., 2017; Fu et al., 2021). China's “Technical Codes for Designing $110 \mathrm{kV}-750 \mathrm{kV}$ Overhead Transmission Lines (GB50545) (2010)" focuses on the GF along the direction representing the maximum velocity and corresponding to several design baseline wind velocity scopes, but few three-component wind-measurement instruments have been applied in studies relevant to the wind power industry. As a result, it is also necessary to confirm whether discrepancies exist in the calculation of TI or GF with data from cup and sonic anemometer instruments to evaluate the reliability and applicability of these instruments in cases in which no 3-component wind-measurement instruments are available, and the canalization effect is ignored.

Considering the importance of the turbulence integral scale (abbreviated TIS) and the power spectral density (abbreviated PSD) of fluctuating winds under the condition of abnormal strong winds and their effects on gust factor estimation and turbulence kinetic energy, which are important considerations for various structural wind-resistance designs (Davenport, 1961; Davenport and Sparling, 1992; Zhou et al., 2017; Kozmar et al.,2021; Liu et al.,2020; ASCE/SEI 7-16, 2017; AIJ, 2019), we examine special cases to characterize the distributions of these parameters compared to international standard codes and typhoon-affected areas in this work. Then, we qualitatively analyze the reliability and application conditions of these parameters. Second, we assess the quantity of wind power from the perspective of climatic probability analysis based on the TI measured in three directions and previous analyses of atmospheric stratified stability (Xin et al., 2015(b)) and wind power loss models (Wharton and Lundquist, 
2012; Rozenn et al.,2010; Lundquist, 2010). Third, to meet the requirements of preventing the swinging of long-span lines or cables in structural engineering industries (An et al., 2019; He et al., 2020; Zhou et al., 2017; Fu et al., 2021), the climatic probability distribution characteristics of the TI under various wind force scales are also revealed. We hope that such work will contribute to wind energy resource development and utilization and promote further research on structural wind engineering models.

\section{Research site information and data preprocessing}

\subsection{Wind measurement environment and study period}

The environmental description of wind mast 31003, including the performance of the cup anemometer and the meteorological elements in 5 layers, have been described in previous studies (Xin et al.,2015(a); Xin et al.,2015(b)). The performance of the WindMaster Pro, which is a 3D ultrasonic anemometer instrument produced by Gill company, at a sampling frequency of $10 \mathrm{~Hz}$ is documented in the study by Su and Xin (2021). The wind-measurement environment and the 3D ultrasonic detector at a height of $70 \mathrm{~m}$ are shown in Figure 1. The cup anemometer data are available from 1 June 2009 to 31 December 2011, and the 3D ultrasonic anemometer data are available from 1 June 2009 to 14 March 2010 and from 13 April 2010 to 30 March 2011.

\subsection{Data quality control method}

All data samples are split and organized into 10 min-length records according to standard time intervals $(T=10 \mathrm{~min}$ ), following wind engineering codes or specifications from China ( $\mathrm{GB} / \mathrm{T}$ 37523, 2019; GB50545, 2010; JTG/T 3360-01, 2018), Japan (AIJ,2019), America (ASCE/SEI 7$16,2017)$ and the WMO (WMO,2018), before the calculation of the TI, GF, TIS, PSD of fluctuating wind.

Except for the removal of bad data according to the quality identification code, logical validations, such as extremes, range, and trend, are performed based on GB/T 37523(2019) for the data from the cup anemometer, including simultaneous consistent validation and reasonableness judgment at various measurement heights. In the event of severe weather, unreasonable data at each level are deduced from nearby Dabanchen Meteorological Station data. At heights greater than $50 \mathrm{~m}$, the difference in the simultaneous extreme wind speed average over a $3 \mathrm{~s}$ time interval between adjacent layers should be less than $10 \mathrm{~ms}^{-1}$; otherwise, it should be less than $5 \mathrm{~m} \mathrm{~s}^{-1}$. After the above steps, 122,787 samples were available for the cup anemometer.

For data quality control from the ultrasonic anemometer, except for rough validations for the longitudinal $(\mathrm{u}(\mathrm{t}))$, lateral $(\mathrm{v}(\mathrm{t}))$, and vertical $(\mathrm{w}(\mathrm{t}))$ directions performed as described above, the data during precipitation are also regarded as invalid, including the period two hours before and after precipitation. In each sample unit, times where any of the velocity components were greater than four times the standard deviation were identified, and the data were removed. Data with spikes in vertical velocity and standard deviations greater than $1 \mathrm{~m} \mathrm{~s}^{-1}$ were also removed. The valid integrity rate of each sample unit lower than $99.8 \%$ was removed from further analysis. 
Therefore, only 30,700 valid samples derived from the ultrasonic anemometer were left in this study.

\subsection{Wind fluctuation extraction and synthetic wind speed derived from the ultrasonic anemometer}

Coordinate rotation, which is the transformation of coordinate systems from the original axes based on the anemometer output to the streamline terrain-following system, is conducted according to the planar fit method (abbreviated PFT) (Richiardone et al., 2008). The extraction of fluctuating velocities $\mathrm{u}(\mathrm{t}), \mathrm{v}(\mathrm{t})$ and $\mathrm{w}(\mathrm{t})$ along the $\mathrm{x}$-axis, $\mathrm{y}$-axis and vertical direction, respectively, follows the processes in JTG/T 3360-01(2018) and the study by Simiu (1996), and the horizontal resultant wind speed is averaged over the $10 \mathrm{~min}$ time interval.

The fluctuating velocities $u(t), v(t), w(t)$ in a time series are the databases of the turbulence parameters, such as the TI, TIS and PSD of fluctuation wind. Here, $t$ is the frequency of sample collection and is $10 \mathrm{~Hz}$, which means that 10 samples are collected every second.

\section{$2.4 \quad$ Turbulence intensity (TI)}

The TI is one of the key statistical parameters to determine the strength of the structural dynamic wind load, which characterizes the magnitude of the fluctuating velocity. It is a function of $\alpha, z_{0}$ and the average velocity from the atmospheric boundary layer (ABL) near the surface. For ultrasonic measurement data, the TI along the longitudinal, lateral and vertical directions is defined as the ratio of the root-mean-square of the fluctuating wind speed $\left(\sigma_{i}, i=u, v, w\right)$ to the mean wind speed within a 10 min base period (JTG/T 3360-01, 2018; IEC61400-1:3,2019; Wharton and Lundquist, 2012; Lundquist,2010; Simiu and Scanlan,1996).

$$
I_{i}=\frac{\sigma_{i}}{U_{u v, T}} \quad(\mathrm{i}=\mathrm{u}, \mathrm{v}, \mathrm{w})
$$

where $\sigma_{i}$ is the root-mean-square of the $\mathrm{u}(\mathrm{t}), \mathrm{v}(\mathrm{t})$, and $\mathrm{w}(\mathrm{t})$ components and $\overline{U_{u v, T}}$ is the resultant mean velocity in a $\mathrm{T}=10 \mathrm{~min}$ base period.

For the measurement data from the cup anemometer, both the mean velocity $\left(U_{T}\right)$ and corresponding standard deviation $(\sigma)$ in the 10 min time interval can be obtained directly from the original datasets; thus, the turbulence strength (I) is determined from the ratio of the known wind speed standard deviation to the mean wind speed averaged over a 10 min time interval (GB 50009, 2012; JTG/T 3360-01, 2018; WMO,2018).

\subsection{Gust factor (GF) and gust peak factor}

The GF is also an important parameter that characterizes the strength of the fluctuation velocity, which is used to convert peak velocities averaged over a short period (e.g., $t_{g}=3 \mathrm{~s}$ ) to mean velocities $\left(\overline{U_{T}}\right)$ averaged over a relatively long reference period (e.g., $\mathrm{T}=10 \mathrm{~min}$ ) or vice versa. In this work, the calculation of GF follows most weather-related wind loading standards or codes for structural engineering (GB 50009, 2012; JTG/T 3360-01, 2018; ASCE/SEI 7-16, 2017; AIJ, 2019; WMO,2018; Simiu and Scanlan,1996), in which the reference period is taken as $\mathrm{T}=10$ min, as in Formula (1), and $t_{g}$ is taken as $3 \mathrm{~s}$. 
For the records obtained from the cup anemometer, the extreme maximum velocity $\left(U_{\text {max }}, \mathrm{tg}\right)$ during a gust duration $\left(t_{g}=3 \mathrm{~s}\right)$ and its corresponding 10 min mean velocity $\left(\overline{U_{T}}\right)$ are known from the raw datasets. Therefore, let $\mathrm{G}$ denote the GF for the cup anemometer data analysis in this study, with $G=U_{\max , t g} / U_{T}$ (JTG/T 3360-01,2018).

For the records obtained from the ultrasonic anemometer, the horizontal resultant maximum velocity during a gust duration $\left(t_{g}=3 s\right)$ is denoted as $\max U_{u v, t_{g}}\left(U_{u v, t_{g}}=\sqrt[2]{\bar{U}_{t_{g}}^{2}+\bar{V}_{t_{g}}^{2}}\right)$ and corresponds to the horizontal resultant mean velocity averaged over the 10 min time interval, which is denoted by $\overline{U_{u v, T}}\left(\overline{U_{u v, T}}=\sqrt[2]{\bar{U}_{T}^{2}+\bar{V}_{T}^{2}}\right)$ and derived from $\mathrm{u}(\mathrm{t})$ and $\mathrm{v}(\mathrm{t})$, as explained in most codes and previous studies (GB/T 37523,2019; JTG/T 3360-01,2018; Burton et al.,2001; Wharton and Lundquist, 2012;Lundquist, 2010; Rozenn et al., 2010; WMO, 2018; Simiu and Scanlan, 1996). Therefore, let $G_{u v}$ denote the composite GF of the ultrasonic anemometer data analysis in the study, $G_{u v}=\max U_{u v, t g} / \overline{U_{u v, T}}$. The GFs of the longitudinal $\left(G_{u}\left(T, t_{g}\right)\right)$, lateral $\left(G_{v}\left(T, t_{g}\right)\right)$ and vertical directions $\left(G_{w}\left(T, t_{g}\right)\right)$ are as follows (Yu and Chowdhury,2009; William and Marshall,1992):

$$
\begin{aligned}
G_{u}\left(T, t_{g}\right) & =1+\frac{\max U\left(T, t_{g}\right)}{\overline{U_{u v, T}}} \\
G_{v}\left(T, t_{g}\right) & =\frac{\max V\left(T, t_{g}\right)}{\overline{U_{u v, T}}} \\
G_{w}\left(T, t_{g}\right) & =\frac{\operatorname{maxW(T,t_{g})}}{\overline{U_{u v, T}}}
\end{aligned}
$$

where $\max U\left(T, t_{g}\right), \max V\left(T, t_{g}\right)$ and $\max W\left(T, t_{g}\right)$ are the maximum mean velocity during gust duration $\left(t_{g}=3 \mathrm{~s}\right)$ along the longitudinal, lateral, and vertical directions, respectively.

The peak factor $(g)$ is the ratio of the maximum wind speed fluctuation to the standard deviation of the wind speed fluctuation; that is, $g=\left(U_{\max , t g}-\overline{U_{T}}\right) / \sigma$ (Cao et al., 2009).

\subsection{Definition of strong gales}

The wind load calculation usually considers the superposition of the average velocity and the fluctuating velocity, mainly focusing on typhoons and strong gales caused by a passing cold front or short-term high-wind mutations caused by a downburst or squall line (GB50545, 2010; An et al.,2019; He et al., 2020; Zhou et al.,2017; Fu et al.,2021; GB50009, 2012; JTG/T 336001,2018;Simiu and Scanlan, 1996; Ishizaki,1983; Choi, 1983; Yu and Chowdhury, 2009; William and Marshall, 1992; Cao et al., 2009). Among them, fluctuating wind, as part of the structural dynamic response in wind load design, is usually characterized by the GF and TI corresponding to different basic wind speeds. For example, China's JTG/T 3360-01(2018) proposes three hazard levels according to the basic wind speed at $10 \mathrm{~m}$ height during the 10-year return period (level R1: $U_{10} \geq 32.6 \mathrm{~m} \mathrm{~s}^{-1}$, R2: $24.5 \mathrm{~m} \mathrm{~s}^{-1} \leq U_{10}<32.6 \mathrm{~m} \mathrm{~s}^{-1}$, R3: $U_{10}<$ $24.5 \mathrm{~m} \mathrm{~s}^{-1}$ ). IEC-61400-3-1(2019) specifies three kinds of reference extreme wind speeds with a recurrence interval of 50 years relating the wind turbine classes inland and one kind for tropical areas. The wind deflection flashover might be given more attention under conditions of wind speeds greater than $10.8 \mathrm{~m} \mathrm{~s}^{-1}$ (An et al., 2019; He et al., 2020; Fu et al., 2021; Zhou et al.,2017). All of these methods, including the ASCE 7-16(2017) and AIJ (2019) codes and Ishizaki's study 
(1983), among others, involve the corresponding GF or TI loading calculation. Therefore, to meet the minimal requirements for structural wind engineering, the strong gale definition for weather-related loads in this study is based on the classification of high wind speeds (the guaranteed rate reaching $99.38 \%$ in all samples from the two types of measurement instruments) while considering the influence of fluctuating winds. Accordingly, for the cup anemometer, strong gales mean that the average wind speed is not less than $22.3 \mathrm{~m} \mathrm{~s}^{-1}$. For the ultrasonic anemometer, the average wind speed is not less than $20.8 \mathrm{~m} \mathrm{~s}^{-1}$.

A total sample of 767 strong gales was selected from the cup anemometer and 190 from the ultrasonic anemometer. Due to the different observation periods, their data quality was different, and there were only 4 synchronous observation records between them.

\section{Results analysis}

\subsection{Overall characteristic differences of the TI between the two measurement instruments}

Figs $2 \mathrm{a}-2 \mathrm{~d}$ show the relationships between the $\mathrm{I}, I_{u}, I_{v}$, and $I_{w}$ and the average velocity at a $70 \mathrm{~m}$ height, respectively. All TI values exhibit declining trends with increasing average velocity, including their scattered distribution trends. However, the TI increases slightly with a mean velocity of high winds above $20 \mathrm{~m} \mathrm{~s}^{-1}$ with respect to the lower winds, representing a clear dividing line. This result is similar to most conclusions that TI values affected by typhoons are higher than those under normal wind conditions before typhoon landfall (Ishizaki, 1983; Choi, 1983; Yu and Chowdhury, 2009; William and Marshall, 1992; Cao et al., 2009). From this view, the definition of strong gales in this study is reasonable in that the range of TI changes in the higher wind stage is not different from that in the lower wind stage. Such high winds with high TI values should be the focus in wind-resistant design.

Figs $2 \mathrm{a}$ and $2 \mathrm{~b}$ also show the NTM reference curves (IEC-A, IEC-B, and IEC-C) for the observations from the cup anemometer and ultrasonic anemometer along the longitudinal direction, as described by IEC 61400-3-1(2019), indicating three expected reference TI values of

$I_{r e f, A}=0.16, I_{r e f, B}=0.14$, and $I_{r e f, C}=0.12$ at $15 \mathrm{~m} \mathrm{~s}^{-1}$ when regarding $I$ as $I_{u}$. Meanwhile, the lateral and vertical expected NTM reference curves are plotted as 0.7 and 0.5 times the longitudinal NTM reference curves, respectively (Figs 2c, 2d). To determine the wind turbine classes, reference TI curves with a $90 \%$ guarantee according to the observed data are calculated by using Formula (38) in IEC 61400-3-1(2019) and denoted as $I_{\text {ref,obs }}, I_{\text {uref,obs }}, I_{\text {vref,obs }}$, and $I_{\text {wref,obs }}$ in Fig $2 \mathrm{a}-2 \mathrm{~d}$, respectively. These TI curves based on observational data ignore the revision required for complex terrain, since the terrain around the 30003 wind mast is smooth and flat. In light of the comparisons between the reference values of the IEC 61400-3-1(2019) NTM and the observational TI reference curves with a $90 \%$ guarantee, including the previously mentioned yearly mean wind velocity and basic wind velocity over a 50 -year return period, a class II wind turbine should be considered based on the cup anemometer and vertical measurements, provided that the wind speed ranges from 10 to $25 \mathrm{~m} \mathrm{~s}^{-1}$; a class I wind turbine is preferred based on the longitudinal measurements; and a class super-I wind turbine should be considered based on the lateral measurements. 
Let us assume that the wind-measurement site is characterized by lower-, middle-, and higherlevel terrain complexity, respectively, according to the description of IEC-61400-3-1(2019); thus, the reference TI curves should be corrected by 1.05-, 1.10-, and 1.15 times the $90 \%$ quantile $I_{\text {ref,obs }}$ of values. Fig 3 displays the comparisons of $I_{\text {uref,obs }}-I_{\text {mod,L }}, I_{\text {uref,obs }}-$ $I_{\text {mod,M }}$, and $I_{\text {uref }, o b s}-I_{m o d, H}$. Meanwhile, to clarify the difference between the $90 \%$ quantile longitudinal $I_{\text {uref,obs }}$, lateral $I_{\text {vref,obs }}$ and $I_{\text {ref,obs }}$ calculations, Fig 3 also presents their discrepancy. From the direct comparisons, we can conclude that the $90 \%$ quantile longitudinal $I_{\text {uref,obs }}$ and lateral $I_{\text {vref,obs }}$ are all greater than that of $I_{\text {ref,obs }}$ and that of $I_{\text {uref,obs }}$ is apparently greater than that of $I_{\text {ref,obs }}$. This means that although the fatigue loading calculations of the wind turbine based on the cup anemometer are corrected by the supposed higher-level terrain complexity category, the designed TI values are still relatively lower compared to the longitudinal values. Specifically, at the bottom of the Dabanchen Canyon, the turbulence might be underestimated by cup anemometer measurements, and even correcting the TI reference values by overstating the local terrain complexity cannot compensate for this gap. In fact, the terrain is relatively flat along the vertical direction and rough along the lateral direction according to comparing the mean values of $\overline{I_{v} / I_{u}}=0.975$ and $\overline{I_{w} / I_{u}}=0.562$ with the definitions of terrain complexity categories in Table 6, as recommended by IEC-61400-31(2019).
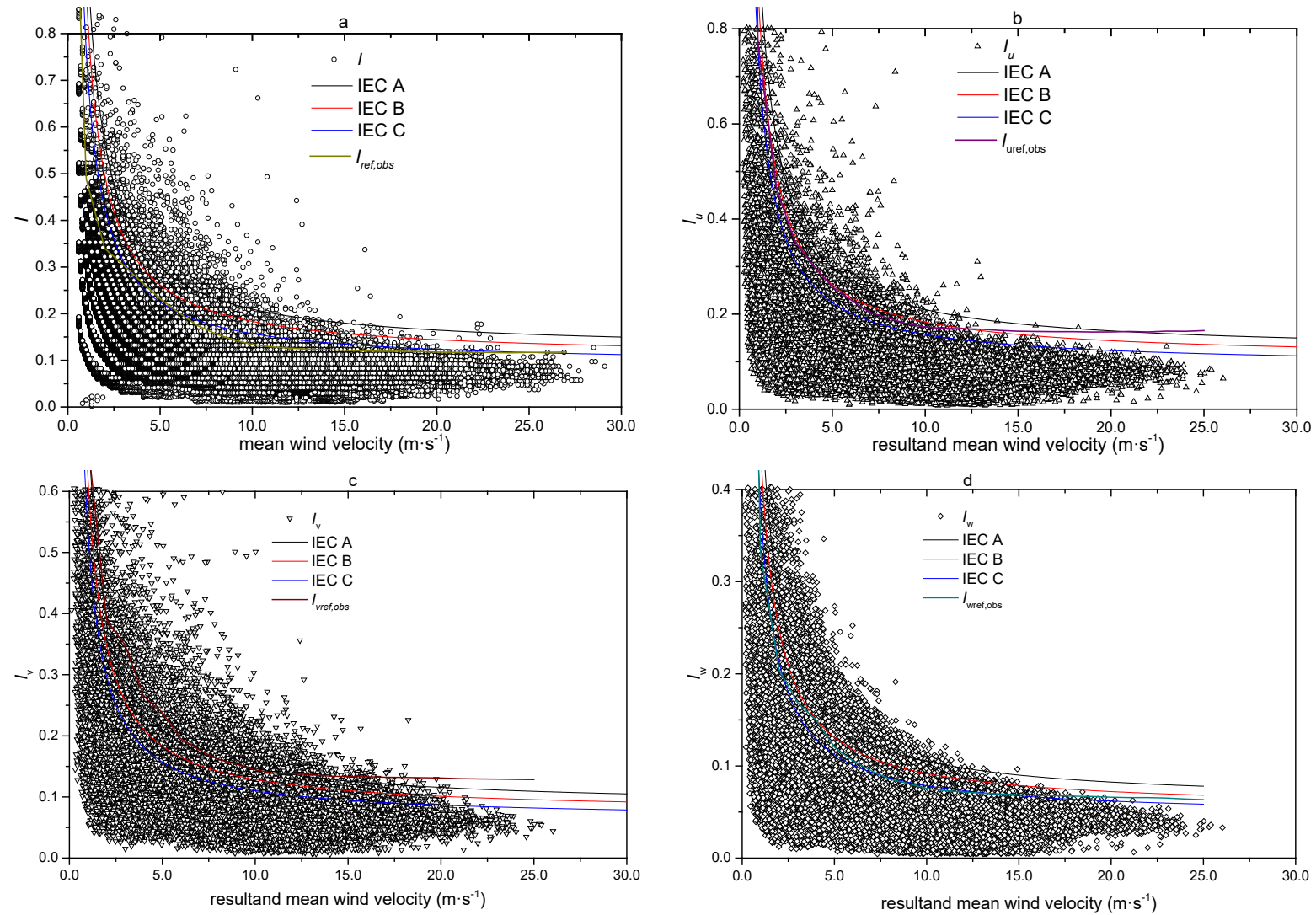

Fig. 2 The relationship between the turbulence intensity and the average wind velocity measured from the cup anemometer (a) and the ultrasonic anemometer including the longitudinal direction $\left(I_{u}\right)(\mathrm{b})$, lateral direction $\left(I_{v}\right)$ (c), and vertical direction $\left(I_{w}\right)(\mathrm{d})$ at $70 \mathrm{~m}$ height. IEC A, IEC B, IEC C denote the normal turbulence intensity curves referencing the 3 types of turbulence magnitudes defined in IEC 61400-3-1(2019). $I_{\text {ref,obs }}, I_{\text {uref,obs }}, I_{\text {vref,obs }}$, and $I_{w r e f, o b s}$ denote the 
fitting turbulence intensity reference curve taking the $90 \%$ quatifile measured by the cup anemometer and the longitudinal, lateral, and vertical turbulence measured by the ultrasonic anemometer, respectively

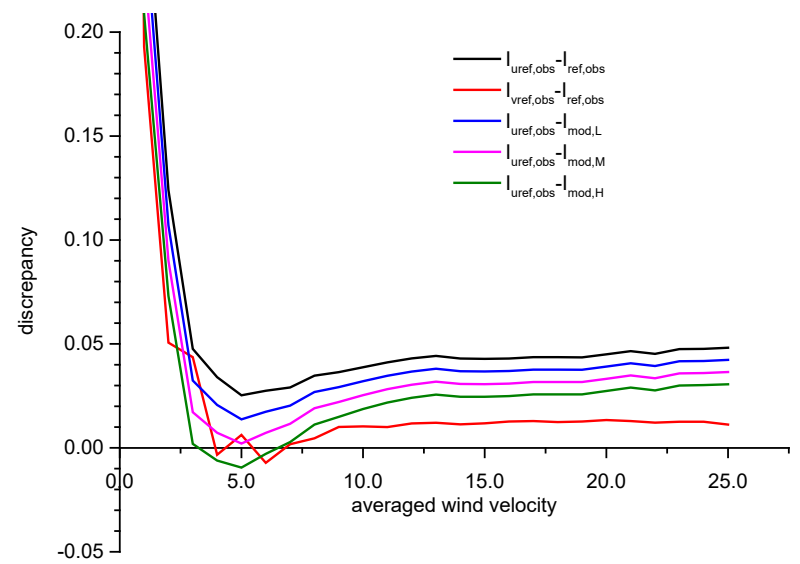

Fig. 3 The discrepancy of wind turbine fatigue loading calculation in the longitudinal $\left(I_{\text {uref }, o b s}\right)$ and lateral $\left(I_{\text {vref,obs }}\right)$ directions compared to that from the cup anemometer data $\left(I_{r e f, o b s}\right)$ at $70 \mathrm{~m}$ height, as well as that in the longitudinal direction compared to that from the cup anemometer data modified by lower-level $\left(I_{\text {mod, } L}=1.05 * I_{\text {ref,obs }}\right)$, middle-level $\left(I_{\text {mod, } M}=1.10 * I_{\text {ref }, o b s}\right)$ and higher-level $\left(I_{m o d, H}=1.15 * I_{\text {ref }, o b s}\right)$ terrain complexity, as recommended by IEC-61400-3-1(2019), which are denoted as

$$
I_{\text {uref }, o b s}-I_{\text {ref,obs }}, I_{\text {vref }, o b s}-I_{\text {ref }, o b s}, I_{\text {uref }, o b s}-I_{\text {mod }, L}, I_{\text {uref }, o b s}-I_{m o d, M} \text {, and } I_{\text {uref }, o b s}-I_{m o d, H}
$$

The above differences can also be confirmed by the comparison of the means averaged over all samples at a $70 \mathrm{~m}$ height: $\overline{\mathrm{I}} \approx 0.103, \overline{I_{u}} \approx 0.143, \overline{I_{v}} \approx 0.137, \overline{I_{w}} \approx 0.080 . \overline{I_{u}}>\overline{I_{v}}>\bar{I}$, which means that the longitudinal and lateral TI derived from the three-dimensional ultrasonic measurements are still higher than those derived from the cup anemometer. This difference is related not only to the absolute magnitude of the vertical fluctuation velocity but also to the response of most cup anemometers rotating faster during the wind speed acceleration stage than during the deceleration stage, resulting in a higher measured average velocity compared to the actual wind speed. WMO (2018) holds that particularly in the case of a larger vertical fluctuation velocity, the velocity measured by the cup anemometer will be higher. The greater the $I_{v}$ is, the higher the $I_{u}$ is compared to that of the cup wind measurements. Both are consistent only if the lateral fluctuation velocity $\mathrm{v}(\mathrm{t}) \equiv 0$ or $\mathrm{v}(\mathrm{y}) / \mathrm{v}(\mathrm{x}) \equiv$ constant. The above statistics reveal that there exists not only a greater $I_{v}$ but also a higher vertical speed and larger wind attack angles of up to 3 degrees due to sloped terrain under near-neutral boundary layer conditions ( $\mathrm{Su}$ and Xin, et al., 2021). These conditions easily produce lower TI values and higher wind velocities measured by the cup anemometer with respect to the ultrasonic anemometer because the former cannot measure such vertical velocity. Therefore, considering the impact of turbulence, the determination of wind turbine classes should prioritize 3-dimensional measurements for such large valleys to avoid a reduction in the designed lifetimes of wind turbine components and higher maintenance costs during the expected operating period. It is a reminder that higher wind with lower turbulence obtained from cup anemometer measurements easily lead to the overestimation of wind energy resources in canyons.

The TI and atmospheric stability have a large influence on the efficiency of wind turbine power collection. Wharton and Lundquist (2012), among others (Lundquist, 2010; Rozenn et al., 2010), have used cup and SODAR gauges to establish an evaluation model with a wind turbine 
collection capacity coefficient by analyzing the effects of individual wind turbines under different atmospheric stability conditions on the TI. Based on the previous atmospheric stability classification demonstrated by Xin (2015(b)) and 3-dimensional TI analysis, this study assesses wind power quality from a climate perspective according to the abovementioned models. The results show that under the conditions of atmospheric stability or strong stability as well as $\mathrm{I}_{\mathrm{u}}<$ 0.10 and $\mathrm{I}_{\mathrm{w}}<0.06$, given the theoretical mechanical efficiency of the wind turbine, the probability of reaching the maximum power collection capacity coefficient is only approximately $42.0 \%$. In the case of near-neutral conditions with $0.10 \leq \mathrm{I}_{\mathrm{u}}<0.20$ and $0.06 \leq \mathrm{I}_{\mathrm{w}}<0.09$, the probability that an equivalent velocity of $8 \mathrm{~m} \mathrm{~s}^{-1}$ on the wind turbine disk will unstably increase the power collection capacity coefficient from $35 \%$ to $70 \%$ is approximately $8.6 \%$. Under the condition of boundary layer instability or strong convection, as well as $\mathrm{I}_{\mathrm{u}} \geq 0.20$ and $\mathrm{I}_{\mathrm{w}} \geq 0.09$, the probability of low-quality wind power causing the wind power collection efficiency to decline by a large magnitude is approximately $50 \%$. In other words, the characteristics of such poor-quality wind power easily causes greater uncertainty in wind energy resources in the canyon.

\subsection{The relative comparison to the longitudinal turbulence intensity}

The high-turbulence situation of $I_{u}>0.18$ and $I_{w}>0.10$ can be found occasionally in Fig $2 \mathrm{~b}$ and $2 \mathrm{~d}$ under wind velocities greater than $10.7 \mathrm{~m} \mathrm{~s}^{-1}$. This situation easily causes overhead transmission lines that pass through the canyon microterrain to shift on the tower side to some extent and vibrates transmission tower facilities to produce wind deflection flashovers, which can reduce the discharge gap and result in heavy rain and lightning around the accidents. The destructive force is the strongest in the event of longitudinal and upwind strong wind turbulence, especially in wind deflection flashover accidents (GB50545,2010; ASCE/SEI 7-16,2017). As a result, wind engineering related to overhead transmission facilities should give more attention to tightening protective measures in the canyon.
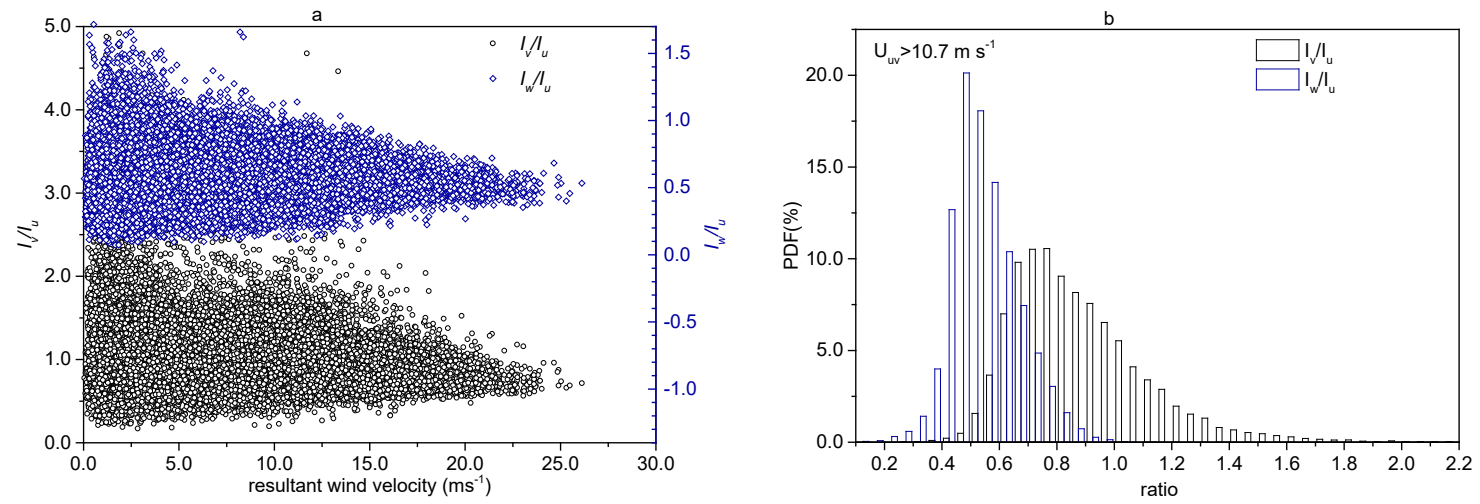

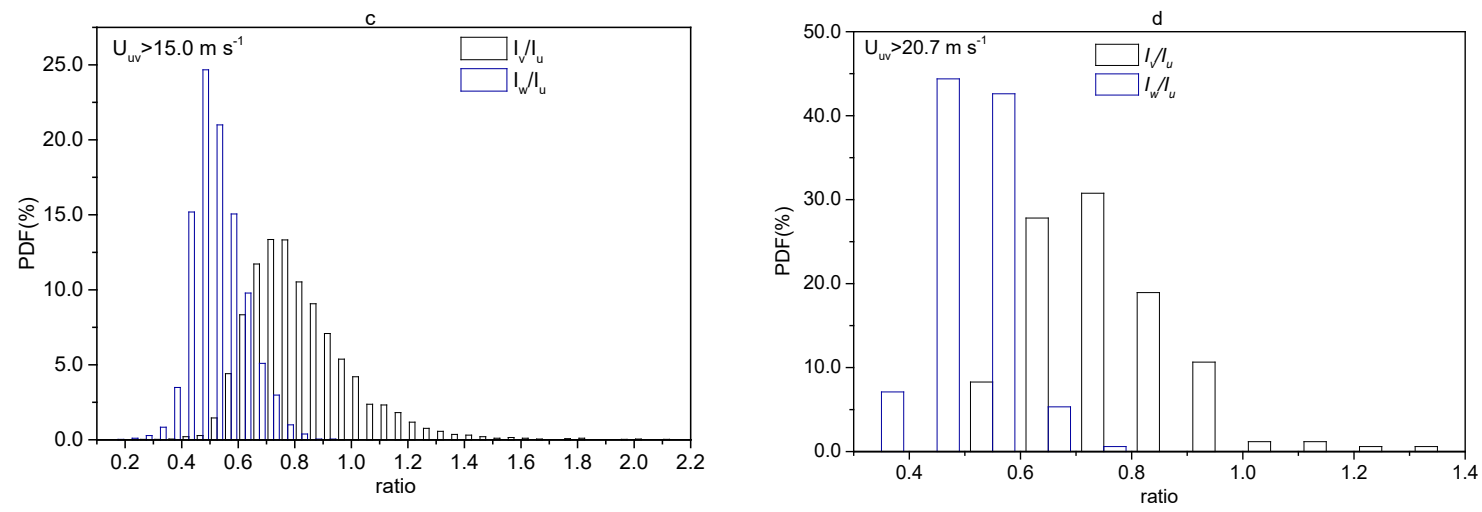

Fig. 4. At $70 \mathrm{~m}$ height, the relationships between turbulence intensity ratios in the lateral direction compared to the longitudinal direction $\left(I_{v} / I_{u}\right)$, those in the vertical direction compared to the longitudinal direction $\left(I_{w} / I_{u}\right)$ and the average resultant wind velocity (a). The probability density function (PDF) comparison between $I_{v} / I_{u}$ and $I_{w} / I_{u}$ under wind velocities greater than 10.7 $\mathrm{m} \mathrm{s}^{-1}(\mathrm{~b}), 15.0 \mathrm{~m} \mathrm{~s}^{-1}(\mathrm{c})$, and $20.7 \mathrm{~m} \mathrm{~s}^{-1}(\mathrm{~d})$.

To reveal the relative importance of the wind speed in all directions, especially in the event of a strong gale, and meet the minimum weather-related wind loading requirements, the relationships between the ratios of $I_{v} / I_{u}$ and $I_{w} / I_{u}$ and the average velocity are presented in Fig 4a, which shows that the dispersions of $I_{v} / I_{u}$ and $I_{w} / I_{u}$ also decrease with increasing wind speed. The ratios of $I_{v} / I_{u}$ and $I_{w} / I_{u}$ at the lower wind stage are significantly greater than those at the higher wind stages. Under high-wind conditions, $I_{u}$ is the largest overall, and $I_{v}$ increases with the wind speed, by approximately $0.8 I_{u}$ on average. For high winds above $20 \mathrm{~m} \mathrm{~s}^{-1}$, an apparent increasing trend with velocity is also observed for the ratios of $I_{v} / I_{u}$ and $I_{w} / I_{u}$. In particular, the ratio of $I_{w} / I_{u}$ increases from 0.34 to 0.72 . This finding demonstrates that the lateral and vertical TI values increase with velocity faster than the longitudinal TI value under higher winds.

To highlight the importance of the TI values in all directions with different wind force levels, Figs $4 \mathrm{~b}-4 \mathrm{c}$ show the probability density function (PDF) of the $I_{v} / I_{u}$ and $I_{w} / I_{u}$ ratios corresponding to resultant wind velocities higher than $10.7,15.0$, and $20.7 \mathrm{~m} \mathrm{~s}^{-1}$, respectively. Among these results, the turbulence structural characteristics with wind velocities $\left(U_{u v}\right)$ greater than $10.7 \mathrm{~m} \mathrm{~s}^{-1}$ are key in the electricity transmission industry (Fig 4b). Fig 4c is that of strong gale events defined by wind velocities $\left(U_{u v}\right)$ greater than $20.7 \mathrm{~m} \mathrm{~s}^{-1}$ based on the ultrasonic anemometer in this work. Figs $4 \mathrm{~b}-4 \mathrm{c}$ demonstrate that on average, $\overline{I_{v}} \approx 0.8 \overline{I_{u}}$ and $\overline{I_{w}} \approx 0.5 \overline{I_{u}}$, and $I_{v}>I_{u}$ occurs more often under the three wind force levels. This conclusion is similar with that presented above. In strong gale events (Fig 4c), when the $I_{v}$ values are higher than the $I_{u}$ values, the variation rates of the ratios of $\mathrm{I}_{\mathrm{u}}, \mathrm{I}_{\mathrm{v}}$, and $\mathrm{I}_{\mathrm{w}}$ are $0.18,0.18$, and 0.20 , respectively, and $\overline{I_{u}}: \overline{I_{v}}: \overline{I_{w}} \approx 1: 0.75: 0.49$. JTG/T $3360-01(2018)$ proposes an empirical ratio of $\overline{I_{u}}: \overline{I_{v}}: \overline{I_{w}} \approx$ 1: $0.88: 0.50$, provided that the data sampled from a wind site are derived under the condition of stable wind variation or stationary synoptic wind in an open, flat area. However, the statistics of strong gale cases show that the probability of $I_{v} / I_{u}>0.88$ is approximately $16.8 \%$, and that of $I_{w} / I_{u}>0.50$ can be up to $48 \%$, while the probability of both conditions occurring simultaneously is approximately $12.6 \%$. This indicates that there might be a small chance of nonstationary strong gale features accompanying abnormal ratios of $I_{v} / I_{u}$ and $I_{w} / I_{u}$ compared to stationary strong ones. This type of strong gale is not applicable to the wind-resistance design of rigid structures, such as bridge engineering. 


\subsection{The differences in the TI between the two measurement instruments affected by strong gale events}

The relationship between the turbulence intensity $(I)$ and wind direction derived from the cup anemometer at a $70 \mathrm{~m}$ height under the condition of strong gales (Fig $5 \mathrm{a}$ ) shows that the $I$ values are far more distributed within the northwest (NW) section than within the southeast (SE) section, and the values in the NW section are significantly higher than those in the SE section. A small number of $I$ extremes are concentrated approximately parallel to the northward direction (N) (i.e., approximately in the direction of the ultrasonic wind downwind), at up to 0.165 . The maximum turbulence intensity measured by the ultrasonic anemometer is 0.14 , coinciding with the longitudinal direction. Thus, the directions of the strongest turbulence measured by the two types of instruments are equivalent. On the other hand, the statistics show that the $\bar{I}=0.107$ averaged over the total samples from the cup anemometer is equivalent to the mean value obtained from only 9 samples with a wind direction close to the northward direction. Therefore, if 3-dimensional measuring instruments were not available, it would be meaningful to use the data distributed in the representative section for a study of strong gales.
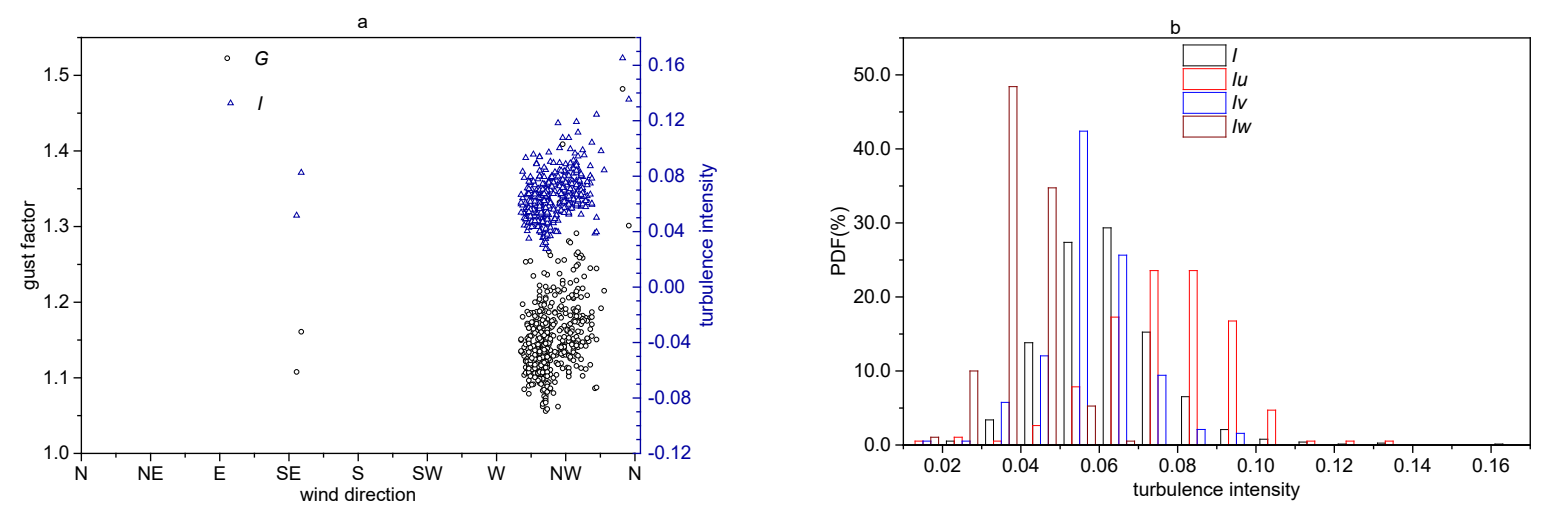

Fig 5 The gust factor $(\mathrm{G})$ and turbulence intensity (I) distributions corresponding to the wind direction (a) and the probability density function (PDF) comparison of the turbulence intensity (I) and the longitudinal $\left(I_{u}\right)$, latitudinal $\left(I_{v}\right)$, and vertical $\left(I_{w}\right)$ turbulence intensities (b) under strong gales.

Under the condition of strong gales, the average $\overline{I_{u}}$ is approximately 0.078 , and the maximal $I_{u}$ is 0.136 . It seems that the average $\bar{I}$ and maximum $I$ obtained from the cup anemometer are higher than the average $\overline{I_{u}}$ and its maximum $I_{u}$ measured by the ultrasonic anemometer, but according to the PDF comparison in Fig $5 \mathrm{~b}$, the $I_{u}$ values are still generally greater than $I$, with $I_{u}$ values mostly between 0.06 and 0.09 and $I$ values mostly between 0.05 and 0.07 . Under the strong gale condition in this study, the chance of $I$ values higher than 0.11 derived from the cup anemometer is approximately $0.52 \%$, and that of $I_{u}$ being close to 0.14 as measured by the ultrasonic anemometer approaches $0.59 \%$. The $I_{u}$ and $I_{w}$ values show a left-tailed distribution, corresponding to a low chance of abnormally small values. From these statistical comparisons, we can conclude that if the sample quantity from the two types of measuring instruments matched or if the selected samples occurred under the same weather conditions, then the maximum $I_{u}$ value may also reach or exceed the maximum $I$ measured onsite.

\subsection{The relationship between the TI and GF in strong gale events}


Fig 5a shows that the direction of TI is consistent with that of GF at a $70 \mathrm{~m}$ height based on 767 samples measured by the cup anemometer under the condition of strong gales. The correlation coefficients listed in Table 1 reveal that very good agreement exists between TI and GF at the 5 layer heights around the 31003 meteorological mast. This statistical relationship between has always been a concern in structural wind engineering. In this paper, we deploy two methods to demonstrate this concept based on these strong-gale samples.

First, a linear fitting analysis of the GF built based on the TI at all levels $\left(G_{z}\right)$ is performed with $G_{z}=1+a I_{z}$, similar to the wind pressure formula $\beta_{z g}=1+2 g I_{10}(z / 10)^{-\alpha}$, in which $I_{10}$ denotes the nominal TI at $10 \mathrm{~m}$ height, $g=2.5$ (constant), $\alpha$ is the wind shear exponent, and $\beta_{z g}$ is the GF at the effective height (z), as described in GB-50009(2012). $I_{z}$ denotes the TI at 10, 30, 50,70 , and $100 \mathrm{~m}$ heights in turn, and $a$ denotes the undetermined coefficient. From the form of both formulas, $a$ and $g$ are consistent in physical relevance, both of which are peak factors that reflect the change in fluctuation wind pressure. Figs 6a-6e and Table 1 provide their correlation relationships. It can be seen that the linear-fitted wind pressure peak factors at all levels obtained from the cup anemometer are slightly less than the defined value of 2.5 in GB-50009(2012). We also calculate the peak factors depicted in Figs 7a-7e from the raw data. It can be found that the variation scope of $g$ with the mean wind speed mostly ranges from 1.5 to 3.5 , and the $g$ of the maximum mean wind speed is close to the corresponding mean value of all samples, as listed in Table 1 . In comparing $g$ estimation by the least-squares fitting method and $g$ calculation by averaging the total peak factor samples, Table 1 shows that both results are approximately equivalent at each level. 

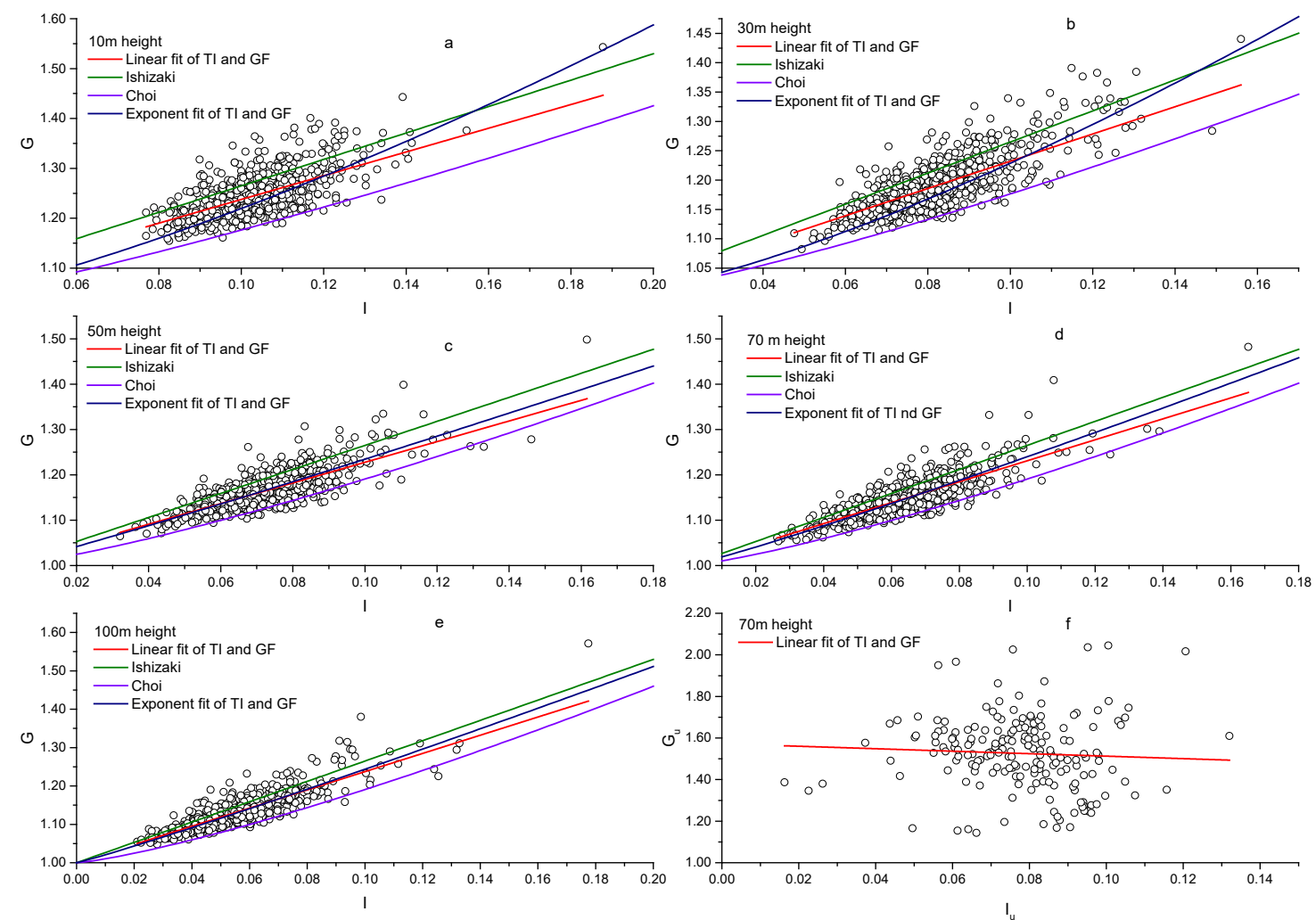

Fig. 6 The correlations between $G$ and $I$ under the condition of strong gales and linear-fitting observation curves as well as exponent-fitting observation curves at $10 \mathrm{~m}$ (a), $30 \mathrm{~m}$ (b), $50 \mathrm{~m}$ (c), $70 \mathrm{~m}$ (d), and $100 \mathrm{~m}$ (e) heights obtained from the cup anemometer measurements compared to the Ishizaki and Choi fitting curves, which refer to areas affected by typhoons. The relationship between $G_{u}$ and $I_{u}$ under strong gales (f).

Table 1 Peak factor $(g)$ values built by TI linear fitting and averaged based on direct observational data calculations, correlation coefficients between GF and TI, and fitting coefficients from Formula (5) at all levels for the cup anemometer under the condition of strong gales

\begin{tabular}{cccccc}
\hline $\begin{array}{c}\text { Measurement } \\
\text { height }(\mathrm{m})\end{array}$ & $\begin{array}{c}\text { Linear-fitted } g \\
\text { from samples }\end{array}$ & $\begin{array}{c}\text { Correlation coefficient } \\
\text { TI and GF }\end{array}$ & $\begin{array}{c}\text { Average } g \text { from } \\
\text { samples }\end{array}$ & $\begin{array}{c}\text { Coefficient } k_{1} \\
\text { in formula 5 }\end{array}$ & $\begin{array}{c}\text { Coefficient } k_{2} \\
\text { in formula 5 }\end{array}$ \\
\hline 10 & 2.3776 & 0.996 & 2.3704 & 1.09 & 1.42 \\
30 & 2.3215 & 0.990 & 2.3000 & 1.06 & 1.39 \\
50 & 2.2765 & 0.986 & 2.2649 & 0.52 & 1.07 \\
70 & 2.3102 & 0.980 & 2.3000 & 0.57 & 1.10 \\
100 & 2.3732 & 0.969 & 2.3560 & 0.54 & 1.07 \\
\hline
\end{tabular}



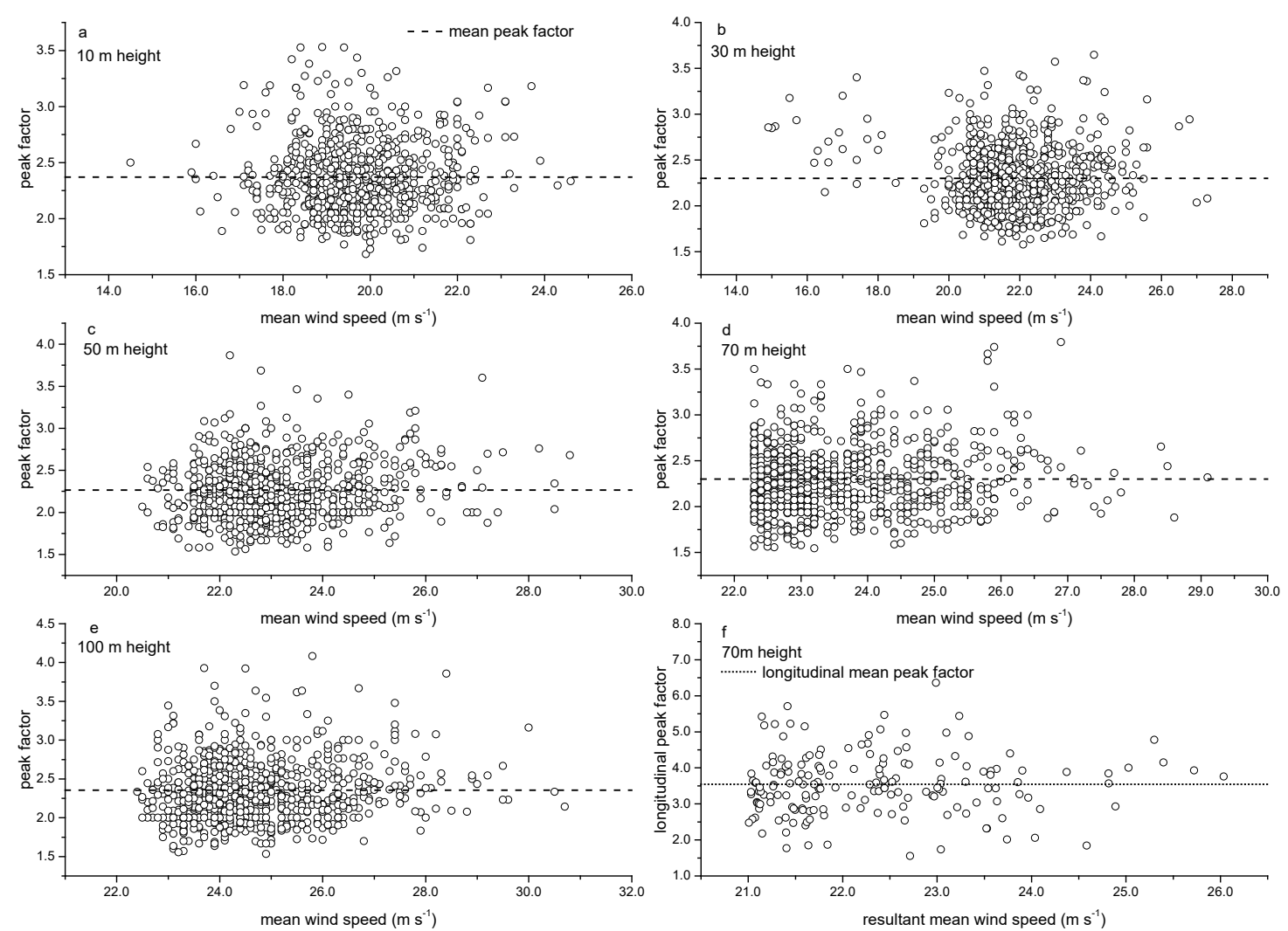

Fig. 7 The relationships between the peak factor and mean wind speed under the condition of strong gales at $10 \mathrm{~m}(\mathrm{a}), 30 \mathrm{~m}(\mathrm{~b})$, $50 \mathrm{~m}(\mathrm{c}), 70 \mathrm{~m}(\mathrm{~d})$, and $100 \mathrm{~m}(\mathrm{e})$ heights, respectively.

Second, many scholars have also studied the functional relationship between TI $(I)$ and GF $(G)$ and concluded that the following functional expression exists:

$$
\mathrm{G}=1+k_{1} I^{k_{2}} \ln \left(\frac{T}{t_{g}}\right)
$$

where $\mathrm{T}$ and $t_{g}$ are as defined in Formulas (1) - (4) and $k_{1}$ and $k_{2}$ are undetermined coefficients. In areas affected by typhoons, Ishizaki (1983) recommends that $k_{1}=0.5$ and $k_{2}=1$ in Formula (5), while Choi (1983) proposes that $k_{1}=0.62$ and $k_{2}=1.27$. Based on Formula (5) and the least-squares fitting method, the best-fitting parameters are obtained and listed in Table 1, and fitting curves at all levels are plotted in Fig 6. Fig 6 reveals that the estimations of GF built by the TI based on Ishizaki's recommendation are slightly higher, by $2-4 \%$, compared to the observed values, and those based on Choi's proposal are obviously lower than the observed values. The higher the measurement level is, the closer Ishizaki's fitting curve approaches to that of the exponent-fitting method. However, it is worth noting that the fitting coefficients built by the TI exponent-fitting method at $10 \mathrm{~m}$ and $30 \mathrm{~m}$ heights are significantly different from those at the other 3 levels.

This result is a reminder that under the condition of strong gales, no correlation between the longitudinal gust factor $\left(G_{u}\right)$ and longitudinal turbulence intensity $\left(I_{u}\right)$ exists, as can be seen in Fig $6 \mathrm{f}$ with respect to the data measured by the ultrasonic anemometer. Consequently, the linear fitting of $G_{u}$ and $I_{u}$ cannot be performed, and Formula (5) is not suitable. In other words, the longitudinal gust peak factor cannot be obtained by any fitting method. Fig $7 \mathrm{f}$ displays the 
relationship between the longitudinal peak factors calculated from 3-component observational data and the resultant mean wind speed. It is obvious that the calculated longitudinal peak factors vary more widely than those calculated from measurements by the cup anemometer, and the longitudinal mean peak factors and their maximal value corresponding to the maximum resultant mean wind speed, which is approximately 3.5, are far greater than those of the fitted values or mean values from the cup anemometer. The longitudinal peak factors at wind speeds greater than $25.0 \mathrm{~m} \mathrm{~s}^{-1}$ are equivalent to those in typhoon-prone regions (Cao, et al. 2009).

\subsection{Gust factor comparison of strong gale events between the two types of measurement instruments}

The PDFs of $G, G_{u v}, G_{u}, G_{v}$, and $G_{w}$ (Fig 8) demonstrate that the $G_{u v}$ values calculated from the ultrasonic anemometer by the wind synthesis method are generally greater than those of $G$ derived from the cup anemometer under the condition of strong gales. This difference occurs mainly because the frequency of $G_{u v}$ values greater than $G$ is higher, ranging from 1.12 to 1.24. However, the statistical dispersion of $G$ from the cup anemometer is larger than that of $G$ from the ultrasonic anemometer. Regardless of the statistical mean, median or mode, not only is the longitudinal GF $\left(G_{u}\right)$ far larger than the maximum $G$ and $G_{u v}, G_{v}$, and $G_{w}$ values, but its statistical dispersion is also the largest, even though $G_{u}$ is the closest to the normal distribution. On average, $\bar{G} \approx 1.252$ near the longitudinal direction, $\overline{G_{u v}} \approx 1.16, \overline{G_{u}} \approx 1.523, \overline{G_{v}} \approx 1.053$, and $\overline{G_{w}} \approx 0.098$. The maximum gust factor value, $G=1.41$ measured by the cup anemometer under wind velocities exceeding $25.0 \mathrm{~m} \mathrm{~s}^{-1}$ is far smaller than that in flat areas affected by typhoons, where the measured gust factor is approximately 1.73 within a $3 \mathrm{~s}$ gust duration with a 1-hour average maximum wind speed ranging from 25 to $30 \mathrm{~m} \mathrm{~s}^{-1}$ at $10 \mathrm{~m}$ altitude and a surface roughness $z_{0}$ ranging from 0.007 to $0.03 \mathrm{~m}$ (Yu and Chowdhury,2009; William and Marshall, 2009), which is equivalent to the local value of $0.02 \mathrm{~m}$ (Xin et al., 2015(b)). However, the longitudinal maximum gust factor, $G_{u}=1.77$, is equivalent to that in the abovementioned areas under the same wind force.

In summary, the higher longitudinal peak factor and longitudinal gust factor are comparable with those of typhoon-prone regions under wind speeds greater than $25.0 \mathrm{~m} \mathrm{~s}^{-1}$ in strong-gale areas.

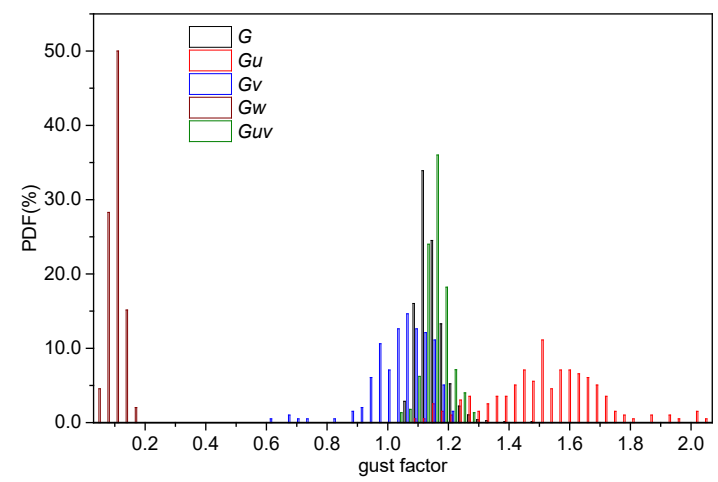

Fig 8. The gust factor ( $\mathrm{G}$ from the cup anemometer), gust factor of the resultant wind $\left(G_{u v}\right)$, and longitudinal $\left(G_{u}\right)$, latitudinal $\left(G_{v}\right)$ and vertical $\left(G_{w}\right)$ gust factors (c) derived from the ultrasonic anemometer (c).

\subsection{Turbulence integral scale (TIS) features under strong gale events}


Atmospheric turbulent motion is a multiscale phenomenon consisting of numerous different scales of turbulent vortices, which are usually characterized by the TIS that reflects the spatial correlation of the fluctuation velocity or wind pressure. The larger the TIS is, the higher the spatial correlation of the fluctuating wind. The TIS is a decreasing function of $z_{0}$ and an incremental function of height and is used as a design reference parameter in wind turbine blade loading or other wind-resistance engineering (JTG/T 3360-01, 2018). The TIS is also related to the height of the boundary layer and the wind speed (ASCE/SEI 7-16,2017; AIJ, 2019). The TIS calculation, $L_{i}^{x}(i=u, v, w)$, is based on the famous Taylor Frozen Theory Hypothesis, assuming that the vortex in the turbulence is transmitted downstream at the average wind speed without decreasing, as obtained by direct integration using a single-point autocorrelated function. The calculation is as follows:

$$
L_{i}^{x}=\frac{\overline{U_{u v, T}}}{\sigma_{i}^{2}} \int_{0}^{\tau_{0.05}} R_{i}(\tau) d \tau(i=u, v, w)
$$

where $\overline{\mathrm{U}_{u v, T}}$ and $\sigma_{i}^{2}$ are as defined in Formula (1). $\tau$ denotes the time delay taking $20 \%$ of the maximum total sample duration, and $R_{i}(\tau)$ denotes the self-autocovariance function of the fluctuation velocity and even function of $\tau$. $\tau_{0.05}$ is the delay time corresponding to the selfcorrelation function dilated reduction from 1 to $0.05 \sigma_{i}^{2}(i=u, v, \mathrm{w})$ under the condition that the self-correlation coefficient is equal to 0.05 .

From the TIS characteristics and the PDFs along the three directions (Figs 9a and 9b, respectively) in strong gale events, it can be seen that overall, $L_{u}^{x}>L_{v}^{x}>L_{w}^{x}$, and the average longitudinal and lateral TIS are approximately $34 \mathrm{~m}$ and $28 \mathrm{~m}$, respectively. The probability of $L_{u}^{x}>L_{v}^{x}$ is approximately $73 \%$ and that of $L_{u}^{x}>L_{w}^{x}$ is approximately $74 \% . L_{u}^{x}$ is mostly between 10 and $60 \mathrm{~m}$ at approximately $96.2 \%$ and between 20 and $45 \mathrm{~m}$ at as much as $71.0 \%$. Most of the $L_{v}^{x}$ scale varies within 10-45 m (approximately 90.7\%) and 15-35 m (up to 69.9\%). Most of the $L_{w}^{x}$ values are characterized by a turbulence microscale average of approximately $22 \mathrm{~m}$, but the statistical dispersion and range are so large that the scale within $1 \mathrm{~m}$ is approximately $25 \%$, while it is approximately $45 \%$ within $5 \mathrm{~m}$ and $88 \%$ within $50 \mathrm{~m}$. There are few differences between $\overline{L_{u}^{x}}$ and $\overline{L_{v}^{x}}$, and the chance of small vortices is high under strong gales.
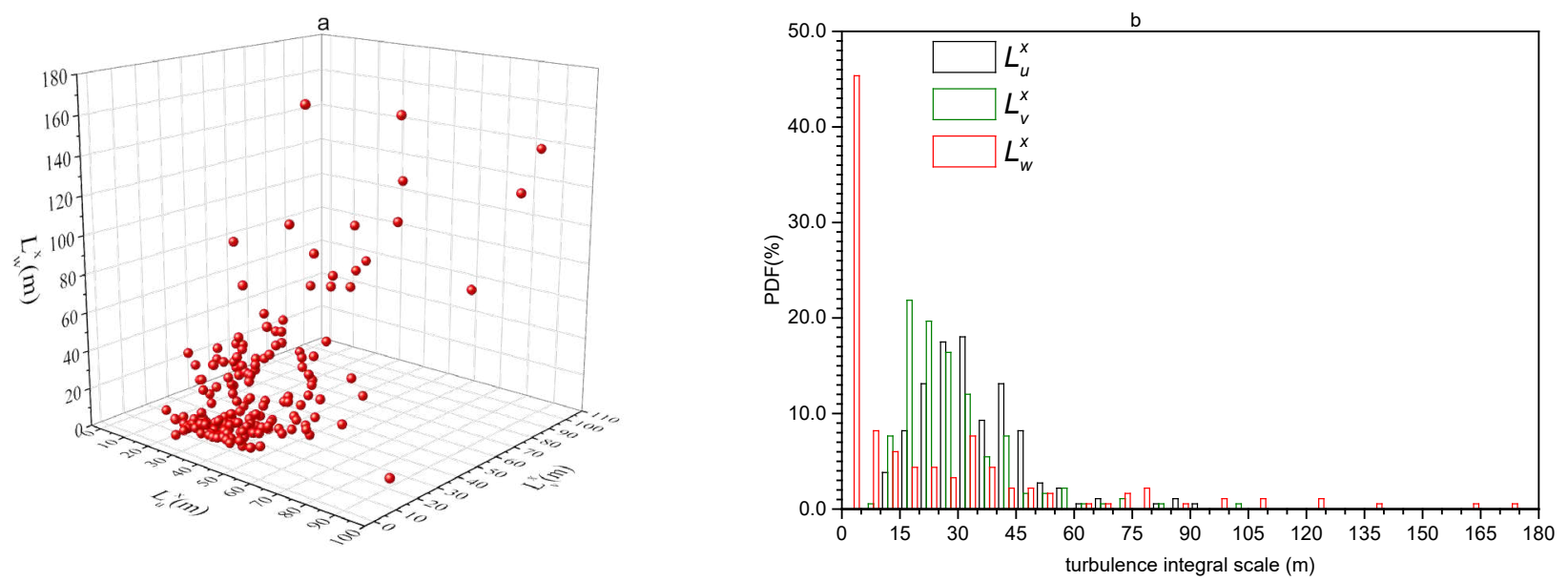

Fig. 9 The distribution of the 3-dimensional turbulence integral scale (a) and the probability density function (PDF) of the longitudinal, lateral and vertical turbulence integral scales (b) under the condition of strong gales 
From the samples of strong gale events observed on site, the maximum values of $L_{u}^{x}$, $L_{v}^{x}$, and $L_{w}^{x}$ are approximately $91 \mathrm{~m}, 100 \mathrm{~m}$ and $171 \mathrm{~m}$. Based on the estimate of the onsite $z_{0}$ (Xin, et al.,2015(b)) as well as the $L_{u}^{x}$ profile calculation, $L_{u}^{x}=280\left(z / z^{\prime}\right)^{0.35}\left(z^{\prime}=1000 z_{0}{ }^{0.18}\right)$ and $L_{u}^{x}=25 z^{0.35} / z_{0}^{0.063}$, proposed by Burton (2001), Erick (2000), etc., the longitudinal TIS ( $\left.L_{u}^{x}\right)$ designed value is approximately $139 \mathrm{~m}$ at a $70 \mathrm{~m}$ height. When deploying the ASCE 7-10 (2017) $\left(L_{u}^{x}=97.54(z / 10)^{1 / 3}\right)$ and AIJ (2019) $\left(L_{u}^{x}=100(z / 30)^{0.5}\right)$ codes, the designed $L_{u}^{x}$ values should be approximately $187 \mathrm{~m}$ and $153 \mathrm{~m}$, respectively, at the same height. When referencing JTG/T 3360-01(2018), the designed $L_{u}^{x}$ should be $120 \mathrm{~m}$. Therefore, the calculated onsite maximal longitudinal TIS $\left(L_{u}^{x}\right)$ is considerably smaller compared to the abovementioned designed TIS in the case of strong gales and is significantly smaller than the impacted area before and after typhoon landfall (Song L L et al., 2010) without a duration of more than $10 \mathrm{~min}$.

The variation rates of $L_{u}^{x}, L_{v}^{x}$, and $L_{w}^{x}$ are $0.40,0.49$, and 1.44 , respectively. Fig $9 \mathrm{~b}$ demonstrates that the vertical TIS $\left(L_{w}^{x}\right)$ values display a far-right-tailed distribution, featuring the greatest discreteness, meaning that the obtained vertical TIS values are very uncertain. The lateral TIS values also display an apparent right-tailed distribution with some uncertainty.

\subsection{Power spectrum density (PSD) of fluctuating wind in the event of strong gales}

The PSD of fluctuating wind, $S_{i}(i=u, v, w)$ in towering structures or tall buildings, is directly focused on calculating the wind vibration coefficient to avoid resonance between wind and structures. It is also an important parameter for calculating the wind turbine blade fatigue characteristics. There are many PSDs of fluctuating wind to describe wind fluctuation characteristics under a neutral boundary layer. Among them, the Kaimal and Simiu empirical spectra are recommended for the anti-fatigue design of wind turbines and towering structural designs (Kaimal et al., 1972; Simiu and Scanlan,1996).

(1) Kaimal (Kaimal et al., 1972) spectrum

The Kaimal spectrum takes into account the change in the PSD with altitude in atmospheric turbulence motion. Its longitudinal expression is as follows:

$$
n S_{u}(n, z) / u_{*}^{2}=\frac{105 f}{(1+33 f)^{5 / 3}}
$$

where $n$ is the sampling frequency $(\mathrm{Hz}) ; z$ is the measurement height, which is $70 \mathrm{~m}$ in this study; and $f$, a dimensionless quantity, is the Monin coordination, $f=n z / U$. The practical meaning of $f$ can be considered as the ratio of the height to the wavelength in the direction of the average wind speed. $u_{*}$, the frictional velocity, characterized by the magnitude of the fluctuation velocity, approximates a constant dependence on the interface smoothness but is not suitable for PSD regularization at the $70 \mathrm{~m}$ height in this study. According to the viewpoint of fluctuating energy, the integration of $S_{i}$ in the full frequency domain is turbulent fluctuating energy, $\sigma_{i}^{2}$, namely, $\int_{0}^{\infty} S_{i}(n) d n=\sigma_{i}^{2}(i=u, v, w)$. Therefore, $u_{*}^{2}$ is replaced by $\sigma_{i}^{2}$. The above symbol descriptions and physical relevance remain the same below.

The lateral PSD expression of the Kaimal spectrum is as follows:

Its vertical expression is as follows:

$$
n S_{v}(n, z) / u_{*}^{2}=\frac{17 f}{(1+9.5 f)^{5 / 3}}
$$

$$
n S_{w}(n, z) / u_{*}^{2}=\frac{2 f}{1+5.3 f^{5 / 3}}
$$


It is worth noting that the original Kaimal spectrum was used to avoid the uncertain estimate effects of the lateral and vertical TIS in this study, which is different from the IEC 61400-3-1 (2019) recommendation for their spectra constructions, in which the TIS and velocity root-mean deviation along all directions are treated as a constant ratio.

(2) Simiu (Simiu and Scanlan,1996) spectrum

The longitudinal Simiu spectrum is a modification of the Kaimal spectrum considering the $f$ influence expressed below:

$$
n S_{u}(n, z) / u_{*}^{2}=\frac{200 f}{(1+50 f)^{5 / 3}}
$$

The lateral Simiu spectrum is as follows:

$$
n S_{v}(n, z) / u_{*}^{2}=\frac{15 f}{(1+9.5 f)^{5 / 3}}
$$

Its vertical spectrum is as follows:

$$
n S_{w}(n, z) / u_{*}^{2}=\frac{3.36 f}{1+10 f^{5 / 3}}
$$

(3) Panofsky (Panofsky and Mccormick,1960) spectrum The Panofsky empirical spectrum is recommended for wind-resistant design specifications for highway bridges in China along the vertical direction (JTG/T 37523, 2018) and is also suitable for most structural wind engineering applications in the vertical direction. The expression is as follows:

$$
n S_{w}(n, z) / u_{*}^{2}=\frac{6 f}{(1+4 f)^{2}}
$$

Hanning smoothing and FFT decomposition are performed for the original sequence before calculating all the measured spectra in the study. Here, three extreme variation cases are selected that represent the maximum longitudinal TI (EXTI), the maximum longitudinal turbulence integral scale (LASC), and the maximum horizontal resultant wind speed (MAXUV).

Figs 10a-c, 10d-f, and 10g-i show the comparison between the measured spectra in all directions and the above empirical spectra, representing the EXTI, LASC, and MAXUV cases, respectively. Table 2 lists the peaks of the PSD and the corresponding peak frequencies. The following can be concluded from these figures and Table 2:

(1) The PSD (i.e., the turbulent kinetic energy) of the EXTI situation is significantly smaller in each frequency domain than in the LASC and MAXUV situations. The peak in the former situation and its peak frequency are also smaller than the others, and the measured spectra of the form in each frequency domain are significantly lower than that of the empirical spectrum. (2) In the LASC and MAXUV situations, the PSD in the high-frequency domain is significantly higher than that of all the corresponding empirical spectra, and the vertical spectrum in the lowerfrequency domain is slightly lower than that of the corresponding empirical spectrum. (3) In all three cases, the patterns of the measured spectra are similar to the Simiu or Kaimal spectra in all frequency domains. The measured vertical spectra do not fit the Panofsky spectrum, which reflects a rapid adaptation to the varied terrain in the high-frequency domain. (4) The peak frequency of the maximum turbulent kinetic energy in all cases is less than $0.2 \mathrm{~s}$. 


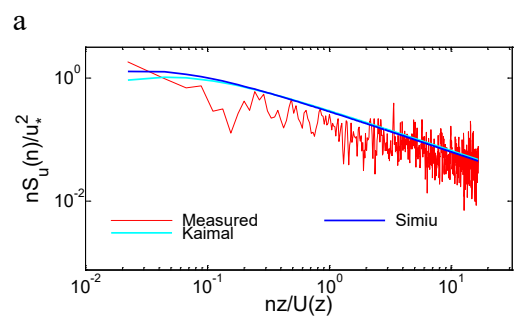

d

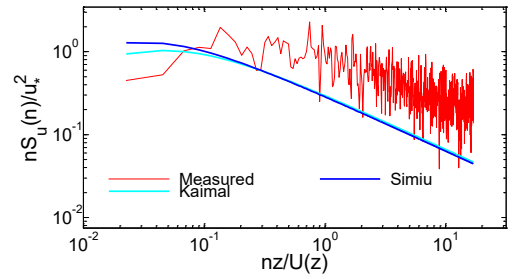

g

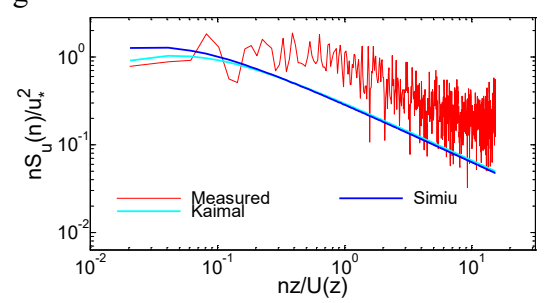

b

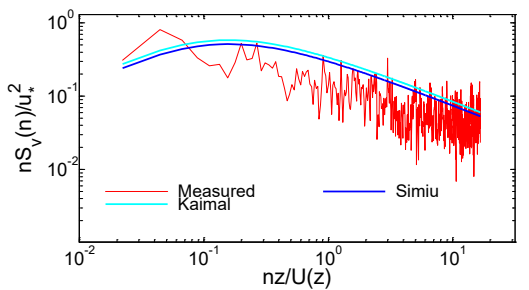

e

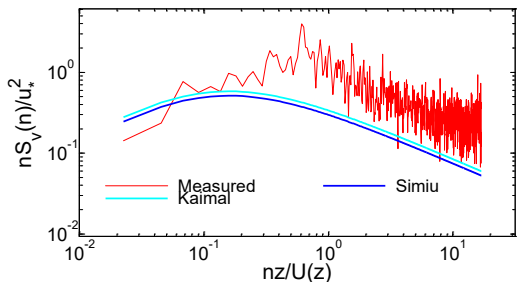

$\mathrm{h}$

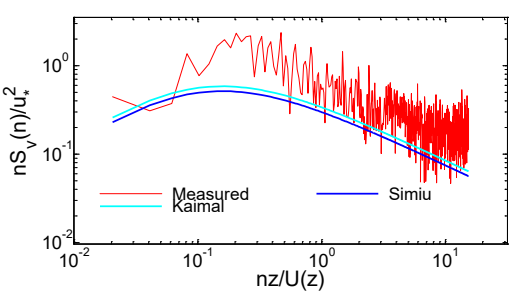

$\mathrm{c}$

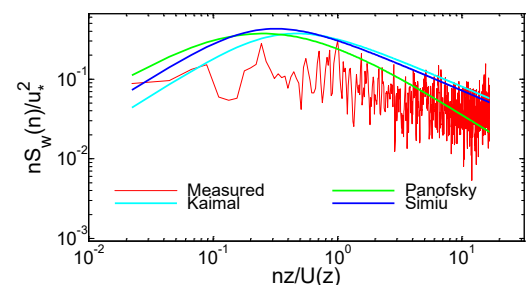

$\mathrm{f}$
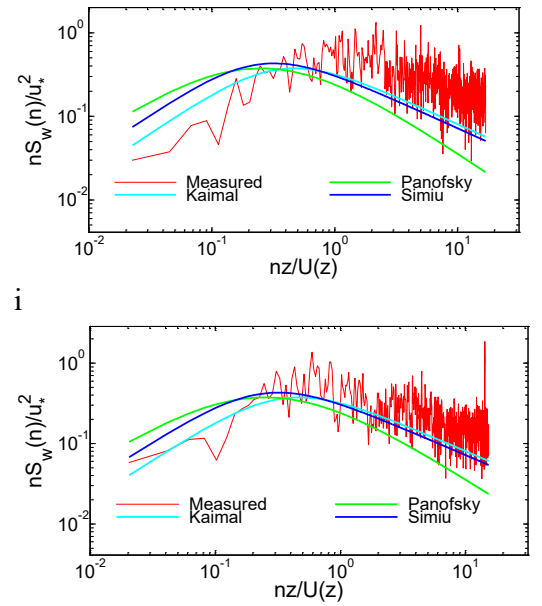

Fig. 10 Comparison between the PSD and empirical spectrum for the longitudinal (a, d, g), lateral (b, e, h) and vertical (d, f, i) wind directions of fluctuating wind under the condition of strong gales and extreme high turbulence intensity (EXTI, a-c), extreme large-scale turbulence (LASC, d-f), and maximal wind velocity (MAXUV, g-i) cases, respectively

Table 2. The maxima of the PSDs of fluctuating winds and corresponding frequencies under typical extremely high winds

\begin{tabular}{llllllllll}
\hline & \multicolumn{3}{c}{ EXTI } & \multicolumn{3}{c}{ LASC } & & \multicolumn{3}{c}{ MAXUV } \\
\cline { 2 - 9 } & Longitudinal & Lateral & Vertical & Longitudinal & Lateral & Vertical & Longitudinal & Lateral & Vertical \\
\hline Peak & 1.8306 & 0.8113 & 0.2809 & 1.9629 & 3.9809 & 0.7413 & 1.8783 & 2.3591 & 1.3722 \\
$\begin{array}{l}\text { Frequency } \\
(\mathrm{Hz})\end{array}$ & 0.0067 & 0.0133 & 0.0733 & 0.0400 & 0.1800 & 0.1600 & 0.1267 & 0.1533 & 0.1933 \\
\hline
\end{tabular}

\section{Conclusions and discussion}

The observation and analysis of atmospheric turbulence intensity is very important to the application of atmospheric physics and wind engineering. The turbulence intensity seems to be essentially a decreasing function of the wind shear exponent, ground roughness length, wind speed, and turbulence integral scale near the ground, but the weather-related wind loading calculations in most wind-resistance codes cannot be directly applied in Dabanchen Canyon, where unstable stratification processes frequently occur, with occasional nonstationary and undesirable strong gales caused by convection processes. As a result, three-component wind observations are necessary for engineering wind-resistance design as well as other meteorological element observations. The characteristics of wind turbulence related to structural design and wind power quality shown in this paper is tentatively useful for the Dabanchen strong-wind area, as follows: 
(1) The longitudinal and lateral turbulence measured by an ultrasonic anemometer are obviously higher than the horizontal turbulence measured by a cup anemometer. Even when the latter is empirically corrected by considering the local terrain complexity to the greatest extent, the data are still lower than the former measurements. This difference is related to the superpositioning of the rotating response performance of a cup anemometer with the dynamic mechanism of the sloped terrain along the canyon, which strengthens the measurement method shortcomings. Similarly, the longitudinal gust factor and peak factor are clearly higher than those calculated from measurements by the cup anemometer under wind speeds exceeding $25.0 \mathrm{~m} \mathrm{~s}^{-1}$. These findings demonstrate that turbulence measurements from a cup anemometer tend to be more underestimated and that three-component anemometers are needed for weather-related wind loading design. Lower turbulence estimations from a cup anemometer leads to the overestimation of wind energy resources. Higher lateral turbulence should be a key consideration, especially in wind turbine fatigue loading design.

(2) Based on ultrasonic anemometer measurements, the wind power quality is not good due to higher turbulence and a higher frequency of unstable stratification processes. Destructive winds occur occasionally and are characterized by wind velocities greater than $10.7 \mathrm{~m} \mathrm{~s}^{-1}$ and longitudinal and vertical turbulence intensities greater than 0.18 and 0.10 , respectively, which easily lead to wind deflection flashover accidents in high-voltage overhead transmission facilities.

(3) Undesirable strong gales, which are characterized by an unstable convective regime with coexisting ratios of the lateral turbulence intensity to the longitudinal turbulence intensity higher than $0.88\left(I_{v} / I_{u}>0.88\right)$ and ratios of the vertical to the longitudinal turbulence intensity higher than $0.50\left(I_{w} / I_{u}>0.50\right)$, occur with a small chance of $12.6 \%$ and should be key concerns for rigid structures, such as in bridge engineering.

(4) The relationships between gust factors and turbulence intensities at all levels from cup anemometers are very good, regardless of whether a linear or exponential function is used, under the condition of strong gales. However, there is no correlation between the longitudinal gust factors and longitudinal turbulence intensities. The longitudinal maximum gust factor (1.77) and maximum peak factor (about 3.5) are comparable to those of typhoon-prone regions under the same wind force (wind speeds exceeding $25.0 \mathrm{~m} \mathrm{~s}^{-1}$ ) and surface roughness.

(5) The longitudinal maximum turbulence integration scale is much smaller than the windresistant design values in the specifications of China (JTG/T 3360-01-2018), Japan (AIJ 2015), and the United States (ASCE 7-10) and much smaller than that of typhoon-affected onshore areas under strong gales. The calculations of the lateral and vertical turbulence integral scales are very uncertain under strong gales.

(6) In the cases of the strongest longitudinal turbulence intensity, the largest turbulence integration scale and the maximum average velocity caused by strong gales, the power spectral densities of fluctuating winds in all three directions are similar to those in the Simiu and Kaimal spectra. In the strongest longitudinal turbulence intensity case, the power spectral densities of fluctuating winds in all directions are lower than those of the corresponding empirical spectra and smaller than those in the other cases. The vertical power spectral densities of fluctuating 
winds in the high-frequency domain in all cases could not reflect the features rapidly adapting to the large terrain. The peak frequencies of the fluctuating wind power spectral densities in all directions are less than $0.2 \mathrm{~s}$ in all cases.

CRediT authorship contribution statement

Yu Xin: Supervision, Conceptualization, Methodology, Software, Data Curation, Resources, Investigation, Validation, Visualization, Formal analysis, Writing - original draft, Funding acquisition. Zonhui Liu: Writing - review \& editing. Qing He: Funding acquisition.

Declaration of Competing Interest

The authors declare that they have no known competing financial interests or personal relationships that could have appeared to influence the work reported in this paper.

Acknowledgments

The authors wish to acknowledge the financial support provided by the National Nature Science Foundation of China for the key project Research of Earth-atmosphere Exchange Process and Atmospheric Boundary Layer Structure in case of Undulating Terrain over Taklamakan Desert (41830968) and the Basic Scientific Operational Research funding of the National Commonweal Research Institute for the project Several Technical Studies Oriented the Near-surface Boundary Layer Prediction Improvement Over Wind Farms (IDM2021007).

\section{References}

An et al.,2019 L Q An, Y Guan, Z J Zhu, R L Zhang

Research on Windage Yaw Flashovers of Transmission Lines under Wind and Rain Conditions

Energies,12(19): 3728; doi:10.3390/en12193728

Architectural Institute of Japan (AIJ), 2019

AIJ recommendations for loads on buildings (2015)

Tokyo: Architectural Institute of Japan

Burton et al., 2001 T Burton, D Sharpe, N Jenkins, E Bossanyi

Wind Energy Handbook

Hoboken: John Wiley \& Sons

Cao et al., 2009 S Cao, Y Tamura, N Kikuchi, M Saito, I Nakayama, Y Matsuzaki

Wind characteristics of a strong typhoon

Journal of wind engineering and industrial aerodynamics, 97(1): 11-21.

Chen and Xin, 2010 Chen H W, Y Xin, P X Chen, Y P Li, X J Yu, S Q Bai

Variation tendency of the extreme value of wind speeds and gale frequency over the windy regions in Xinjiang

Climatic Environmental Research,15(4): 479-490.

Choi, 1983 E C C Choi

Wind loading in Hong Kong: commentary on the code of practice on wind effects Hong Kong

Hong Kong: Hong Kong Institution of Engineers

Davenport, 1961 A G Davenport

The spectrum of horizontal gustiness near the ground in high winds

Journal of the Royal Meteorological Society, 87 (372): 194-211.

Davenport, 1992 A G Davenport, B.F Sparling

Dynamic gust response factors for guyed towers

Journal of Wind Engineering and Industrial Aerodynamics, 43(1-3): 2237-2248.

Erich, $2000 \mathrm{H}$ Erich

Wind Turbines-Fundamentals, Technologies, Application and Economics

New York: Springer.

Fu et al., 2021 X Fu, W L Du, H N Li, L REN

On-Site Measured Gust Response Factors of Transmission Towers Based on SHM System

Journal of Aerospace Engineering,34(1): 04020104; DOI: 10.1061/(ASCE) AS.1943-5525.0001218

GB50009-2012, 2012 GB50009-2012

Load Code for the Design of Building Structures

Beijing: China Building Industry Press 
GB50545, 2010 GB50545

Technical Codes for Designing $110 \mathrm{kV}-750 \mathrm{kV}$ Overhead Transmission Lines

National Standard of P.R. China, Planning Press, Beijing, China

GB/T 37523-2019, 2019 GB/T 37523-2019

Specification for data inspection and correction of wind power plant meteorological observation

Beijing: Standards Press of China

He et al., 2020 P He, J C Han, Y J Li, C He, W K Xiao

Research on Failure Mechanisms of Broken Strands of Jumper Wires for EHV Transmission Lines in Strong-Wind Areas

Metals, 10(1): 39; doi:10.3390/met10010039

International Electro-technical Commission (IEC) 61400-1:3, 2019

Wind Turbines-Part1: Design requirement (edition3.1)

Geneva: IEC Central Office

Ishizaki, $1983 \mathrm{H}$ Ishizaki

Wind profile, turbulence intensities and gust factors for design in typhoon-prone regions

Journal of Wind Engineering and Industrial Aerodynamics, 13(1):55-66.

JTG/T 3360-01,2018 JTG/T 3360-01

Wind-resistant Design Specification for Highway Bridges

Beijing: China Communications Publishing \& Media Management Co., Ltd,2018.

Kaimal et al., 1972 J C Kaimal, J C Wyngaard, Y Izumi, O R Cote

Spectral characteristics of surface layer turbulence

Qurart J. Royal Meteorol. Soc., 98(417):563-589.

Kozmar et al., 2021 H Kozmar, G Bartoli, C Borri

The effect of parked wind turbines on wind flow and turbulence over a complex terrain

Wind Energy, 24(4):1337-1347. DOI: 10.1002/we.2629.

Li et al., 2012 X Li, X Xia, Y Xin, Y Ma, J Yang, J Li

An examination of boundary layer structure under the influence of the gap winds in Urumqi, China, during air pollution episode in winter

Journal of the Air and Waste Management Association, 62(1):26-37.

Liu et al., $2020 \mathrm{Z}$ Q Liu, S Y Lu, T Ishihara

eddy simulations of wind turbine wakes in typical complex topographies

Wind Energy, 24(8): 857-886; doi.org/10.1002/we.2606.

Lundquist 2010, J K Lundquist

Observational needs for wind resource assessment and forecasting

American Meteorological Society Short Course on Wind Energy.

Panofsky and Mccormich, 1960 H A Panofsky, R A Mccormick

The spectrum of vertical velocity near the surface

Quart J. Royal Meteorol. Soc., 86(370):546-564.

Ren et al., 2018, G R Ren, J F Liu, J Wan, F Li, Y F Guo, D R Yu

The analysis of turbulence intensity based on wind speed data in onshore wind farms

Renewable Energy, 123: 756-766.

Richiardone et al., 2008, R Richiardone, E Giampiccolo, S Ferrarese, M Manfrin

Detection of Flow Distortions and Systematic Errors in Sonic Anemometry Using the Planar Fit Method

Boundary-Layer Meteorology, 128(2), 277-302. doi:10.1007/s10546-008-9283-0, 2008.

Rozenn et al., 2020 W Rozenn, C Michael, J L Torben, S P Uwe

Simulation of shear and turbulence impact on wind turbine power performance

Denmark Technical University: Wind Energy Report, 2010.

Simiu and Scannal, 1996 E Simiu, R H Scanlan

Wind Effects on Structures Fundamentals and Applications to Design

New York: John Wiley \& Sons, 1996.

Song et al. 2010 L L Song, J B Pang, C L Jiang, H H Huang, P Qin

Field measurement and analysis of turbulence coherence for Typhoon Nuri at Macao Friendship Bridge

SCIENCE CHINA Technological Science, 53(10):2647-2657.

Structural Engineering Institute of the American Society of Civil Engineers (ASCE/SEI7-16), 2017 Structural Engineering Institute of the American

Society of Civil Engineers

Minimum design loads for buildings and other structures

Reston: American Society of Civil Engineering

Su and Xin, 2021 X L Su, Y Xin, H J Zhang, X J Yu, Y Z Zhao, Y P Li

Studies on Wind Engineering Parameter Characteristics of Complex Terrain in Dabanchen Canyon

Meteorological and Environmental Science, 44(6):59-67.

Wharton and Lundquist, $2012 \mathrm{~S}$ Wharton, J K Lundquist

Atmospheric stability affects wind turbine power collection

Environment research letters, $7: 1-9$

William and Marshall, 1992 R K William, R D Marshall

Gust Factors Applied to Hurricane Winds

Bulletin American Meteorological Society, 73(5): 613-618

World Meteorological Organization (WMO), 2018, World Meteorological Organization

Guide to Meteorological Instruments and Methods of Observation: (WMO-No. 8 Volume I - Measurement of Meteorological Variables)

Geneva: Publications Board World Meteorological Organization (WMO)

Xin et al., 2015(a) Y Xin, X J Yu, H W Chen

Verification of wind forecasts at funneling wind area in Xinjiang by two background field improving schemes

Journal of Desert Research, 35(4): 994-1005.

Xin et al., 2015(b) Y Xin, Y Z Zhou, L L Song, H M Jiang

Aerodynamic roughness comparison between the estimated based on masts and the defined in model over Xinjiang wind areas

Transactions of Atmospheric Science, 38(6): 811-818.

$\mathrm{Yu}$ and Chowdhury, $2009 \mathrm{~B} \mathrm{Yu,} \mathrm{A} \mathrm{G} \mathrm{Chowdhury}$

Gust factors and Turbulence Intensities for the Tropical Cyclone Environment 
Journal of Applied Meteorology and Climatology,48(3):534-552.

Zhou et al., 2017 R Zhou, W Gao, D Zhao

Improved calculation model for swing angle of suspension insulator string

IET Generation Transmission Distribution, 11(14): 3644-3653. doi.org/10.1049/iet-gtd.2017.0904 